\title{
3D mapping efficacy of a drone and terrestrial laser scanner over a temperate beach- dune zone
}

Guisado-Pintado, E., Jackson, DWT., \& Rogers, D. (2019). 3D mapping efficacy of a drone and terrestrial laser scanner over a temperate beach-dune zone. Geomorphology, 328, 157-172. https://doi.org/10.1016/j.geomorph.2018.12.013

Link to publication record in Ulster University Research Portal

\section{Published in:}

Geomorphology

Publication Status:

Published (in print/issue): 01/03/2019

DOI:

10.1016/j.geomorph.2018.12.013

\section{Document Version}

Author Accepted version

\section{General rights}

Copyright for the publications made accessible via Ulster University's Research Portal is retained by the author(s) and / or other copyright owners and it is a condition of accessing these publications that users recognise and abide by the legal requirements associated with these rights.

\section{Take down policy}

The Research Portal is Ulster University's institutional repository that provides access to Ulster's research outputs. Every effort has been made to ensure that content in the Research Portal does not infringe any person's rights, or applicable UK laws. If you discover content in the Research Portal that you believe breaches copyright or violates any law, please contact pure-support@ulster.ac.uk. 


\section{Accepted Manuscript}

3D mapping efficacy of a drone and terrestrial laser scanner over a temperate beach-dune zone

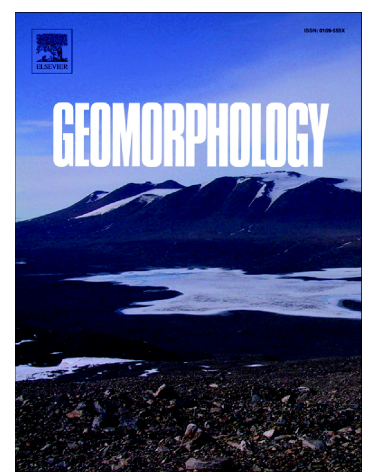

Emilia Guisado-Pintado, Derek W.T. Jackson, David Rogers

PII: S0169-555X(18)30504-X

DOI: https://doi.org/10.1016/j.geomorph.2018.12.013

Reference: GEOMOR 6612

To appear in: Geomorphology

Received date: 31 July 2018

Revised date:

13 December 2018

Accepted date:

16 December 2018

Please cite this article as: Emilia Guisado-Pintado, Derek W.T. Jackson, David Rogers, 3D mapping efficacy of a drone and terrestrial laser scanner over a temperate beach-dune zone. Geomor (2018), https://doi.org/10.1016/j.geomorph.2018.12.013

This is a PDF file of an unedited manuscript that has been accepted for publication. As a service to our customers we are providing this early version of the manuscript. The manuscript will undergo copyediting, typesetting, and review of the resulting proof before it is published in its final form. Please note that during the production process errors may be discovered which could affect the content, and all legal disclaimers that apply to the journal pertain. 
3D mapping efficacy of a drone and terrestrial laser scanner over a temperate beach-dune zone

Emilia Guisado-Pintado ${ }^{a, b}$, Derek W.T. Jackson ${ }^{b}$ and David Rogers ${ }^{b}$

${ }^{a}$ Department of Physical Geography and Geographic Regional Analysis. Universidad de Sevilla. c/ Maria de Padilla s/n. Seville, 42004. Spain. eguisado@us.es

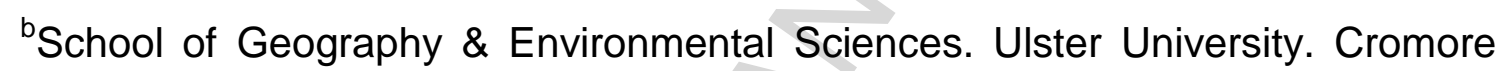
Road, Coleraine Northern Ireland BT52 1SA (U.K.). d.jackson@ulster.ac.uk; dwr.rogers@ulster.ac.uk

Corresponding author: Emilia Guisado-Pintado; eguisado@us.es 


\section{Abstract}

Understanding dynamic earth surface processes requires various spatial and temporal information to help produce patterns of landform change. Recent developments in sensor technology such as Structure from Motion (SfM), camera-mounted airborne Unmanned Aerial Vehicles (UAVs) and Terrestrial Laser Scanning (TLS) have provided a means of acquiring high-resolution spatial data on land surface topography. Through repeat surveys, these techniques enable much better understanding of what is termed 'geomorphometry', where we can examine a geomorphic surface for change over space and time. In coastal environments, change can involve significant alteration and generation of landforms over relatively short periods and, therefore, we require a means of measuring surface morphology quickly and over large areas. Here, we examine a section of a beach-dune system in NW Ireland using SfM-UAV and TLS plus baseline dGPS data points to assess the value of these techniques and to understand their effectiveness (and limitations). Issues such as accuracy, resolution and differences of Digital Elevation Models (DEMs) are assessed for their efficiency, associated challenges and relative performance over variations in terrain types and analytical approaches. We also examine the implications for differences in areal and volume calculations of the coastal landforms using the both approaches. We find that sensor performance is highly dependent on the terrain being measured, with undulations, slope, vegetation cover, acquisition resolution (point density) and interpolation issues all having pronounced impacts on effectiveness and data quality. In general, the TLS performed better over flatter, low-angled topography containing sparse/non-vegetated areas than in areas 
with complex landforms where survey shadows appear to compromise final DEMs. The SfM-UAV shows good performance over different terrains with the exception of relatively flat, featureless areas such as sandy beaches and densely-vegetated surfaces where differences between techniques are greater than $1 \mathrm{~m}$. Data acquisition however is much (x30) faster using a SfM-UAV with more extensive survey areas covered than using a TLS.

Keywords: Structure from Motion, TLS, UAV, DEMs, beach morphologies, temperate regions. 


\section{INTRODUCTION}

The study of earth surface processes relies on multiple environmental datasets and within dynamically changing environments, three-dimensional digital elevation model (DEMs) are normally used to help quantify morphological change patterns (Pike, 1995, 2000; Evans et al., 2003; Hengl and Reuter, 2008). Coastal systems in particular are affected by numerous environmental factors (sediment inputs, climate and meteo-marine conditions, vegetation and human activity etc.) that exhibit seasonal fluctuations and operate at a range of spatial scales (Carter, 1988). Understanding and monitoring of these factors and their influence in coastal-dune geomorphological evolution is thus challenging but is normally undertaken using regular topographic campaigns (Fabbri et al., 2017). Further, monitoring geomorphic change requires highresolution DEMs capable of capturing what can be significant alterations in coastal-landscape shape and extent even after single episodic events such as oceanic storms (Guisado-Pintado and Jackson, 2018).

Only in the last 10-15 years have we seen significant developments in sensor equipment to provide researchers with vast quantities of 3D spatial data. Use of ground-based Global Position Systems (GPS) topographic information and aerial photography represent the early phases of recent developments in the field, where DEMs were created using photogrammetry and validated by ground GPS surveys (Chisholm, 1977; Chandler et al., 1989; Chandler, 1999; Lane, 2000; Brasington et al., 2003). 
Recently, we have seen the introduction of land- and air-based solutions for high-resolution surface topographic data including airborne LiDAR, Unmanned Aerial Vehicles (UAV) and derived Structure from Motion (SfM) and Terrestrial Laser Scanners (TLS), all linked to positional GPS information. This rapid acquisition of topographic data is now possible at spatial resolutions and extents previously inconceivable (Lane and Chandler, 2003; Heritage and Hetherington, 2007) and has resulted in huge advances in monitoring geomorphic changes through repeat topographic surveys (Wheaton et al., 2010). Research areas such hydrology, land-use, archaeology, natural hazards and computer science (Sofia et al., 2016), and more recently seafloor geomorphometry (Lecours et al., 2015, 2016), are benefitting from these advances.

TLS scanning provides a high spatial-resolution spread of survey points, particularly in areas where detailed analysis of surface change is needed. Preliminary studies (Bechet et al., 2016) show the huge potential of TLS to measure and map surface erosion at very fine scales (millimetre) and at shortrange distances (Abellán et al., 2009; Nield and Wiggs, 2011). The laser of the TLS has a footprint that increases in diameter with increasing distances to the target and high frequency scanning produces a dense grid of points representing the targeted area (Nield et al., 2011; Baddock et al., 2017). Distance from scanner position, terrain and slope, however, lead to an uneven distribution of TLS points across and along the surveyed area. Thus, a regridding and interpolation process is a fundamental step in conventional digital elevation modelling (Li et al., 2004; Hancock, 2006; Bater and Coops, 2009; 
Hilker et al., 2010; Rodríguez-Caballero et al., 2016) and is one of the main influences on accuracy achieved (Hancock, 2006; Bater and Coops, 2009). Amongst all the interpolation methods, 'Near-neighbour' or 'Natural Neighbour' has been proved to be the most effective in use at smoothing dense TLS points (Wang et al., 2011, 2013; Zhou et al., 2017), although other methods such as Inverse Distance Weighted are also used (Montreuil et al., 2013a). The final quality of the DEM generated, however, is also dependent on the field survey strategy adopted. For example, ensuring overlapping scans (Pirotti et al., 2013) as well as decreasing the incident angle of the TLS laser helps increase the likelihood of more efficient penetration through any vegetation canopy and therefore ground returns (Nield and Wiggs, 2011). Further, the terrain slope and soil type can influence TLS returns (Baltensweiler et al., 2017). Low stature plants can make it difficult to distinguish between ground and plant elevations in coastal marshes (Guarnieri et al., 2009) whereas dense grassland saltmarsh and other vegetated habitats normally require a type of vegetation filtering (Heritage and Hetherington, 2007; Coveney and Fotheringham, 2011; Pirotti et al., 2013). Finally, using a TLS in association with GPS data helps achieve more accurate datasets in the presence of vegetation for derived DEMs (Coveney et al., 2010).

Photogrammetry is a well-established method that takes advantage of digital image processing to generate 3D models. Early applications focussed on producing DEMs using both photogrammetric principles and GPS (Lane et al., 1994; Lane, 2000; Brasington et al., 2003). More recently, the development of the Structure from Motion (SfM) methods, based on stereoscopic principles, 
have proved useful in producing 3D surface models using overlapping images from multiple viewpoints (e.g. James and Robson, 2012; Fonstad et al., 2013). When mounted on UAVs, these offer a low-cost, flexible and versatile alternative for acquiring high-resolution remote sensing data. Previous studies from Micheletti et al. (2015a) have stimulated a wide community of geoscientists (including non-experts) to use SfM photogrammetry as a key tool in generating 3D models and developing digital surface mapping over various scales (Eltner et al., 2016). However, some limitations still exist in SfM. For example, understanding the influence of survey design over complex morphologies (Westoby et al., 2012; Eltner and Schneider, 2015) and the critical role of a dense deployments of carefully measured GCPs and their inclusion in the image processing (Micheletti et al., 2015a; Micheletti et al., 2015b; Coveney and Roberts, 2017; James et al., 2017a, 2017b) are important considerations. Camera calibration, lens distortion and a derived 'doming' effect also play an important role in final surfaces derived (James and Robson, 2012; Eltner and Schneider, 2015; Carbonneau and Dietrich, 2017; O'Connor et al., 2017). The effect of surface texture, particularly in vegetated areas and in flat or low texture environments, are difficult for image reconstruction (Mancini et al., 2013; Eltner et al., 2015) as well as a varying camera altitude relative to ground surfaces which ultimately complicates image matching (James et al., 2017a). Other important aspects such as the influence of illumination conditions in off-nadir flights needs to be considered to create contrast within homogeneous surfaces (James and Robson, 2012; Gienko and Terry, 2014; Gómez-Gutiérrez et al., 2015; Seymour et al., 2018). All these aspects are important in the quality level achieved for the final 3D surface model (Eltner et al., 2016). Some of the latter 
are still not properly addressed within geomorphology given that most photogrammetric processing by researchers is usually conducted using 'black box' software (James et al., 2017b).

SfM and TLS techniques generate dense point clouds (PC) of $3 D$ data of the landscape, rapidly propelling these as the 'new generation' of field approaches for understanding geomorphometry in coastal environments. The exploitation and challenges in the use of these remote sensing applications in coastal geomorphology has been reviewed by French and Burningham (2009). For instance, Westoby et al. (2012) and Ružić et al. (2014) tested the capabilities and performance of SfM to produce surface models of complex coastal cliffs. Other studies have used the SfM to build 3D models of coastal boulders (Gienko and Terry, 2014) whereas Harwin and Lucieer (2012), and more recently Casella et al. (2016), assessed the spatial and temporal accuracy of an UAV-based image capture to map and monitor natural coastal landscapes. Similarly, the use of TLS in coastal environments has increased in the past decade; studies of beach nourishment (Pietro et al., 2008), monitoring of small bedforms and aeolian systems (Mancini et al., 2013; Montreuil et al., 2013b; Pelletier and Jerolmack, 2014; Baddock et al., 2017; Fabbri et al., 2017; Smith et al., 2017) are just some examples. In all cases, the ultimate goal of using these technologies is the quantification of volumetric and areal changes between successive topographic surveys by the application of Geomorphic Change Detection (GCD) concept (James et al., 2012) and producing a DEM of Difference (DoD). 
All of the above examples have focused in the use of either the TLS or the SfM and have successfully demonstrated that although both do help overcome classical problems of poor spatial resolution when quantifying topographic changes, some limitations remain when they are used in the presence of dense vegetation and over low relief/texture areas. However, only Westoby et al. (2012), Mancini et al. (2013), and more recently, Seymour et al. (2018) and Medjkane et al. (2018), partially combined both techniques in a coastal cliff section and over a low relief coastal area, to compare results and their relative performances. However, none of the above studies account for vegetation filtering correction, particularly over highly variable terrain within temperate coastal beach-dune environments.

This study assesses the applicability, limitations and effectiveness of using TLS and SfM-UAV techniques for 3D mapping when used over a complex beachdune system in north western Ireland. Rather than using a monotype environment (as in previous studies e.g. Casella et al., 2016), we have used a study area with a range of terrain types incorporating a flat beach, cobble ridge, sparsely vegetated foredune up to a well-developed (>20 m) and fully vegetated dune system. We present an approach for the application of vegetation filters for TLS and SfM-UAV based on the use of GPS as a benchmark across this range of surface terrain to better elucidate the major sources of error in DEMs. The work examines for the first time, which technique may be better suited to monitor particular coastal beach-dune morphologies and types within temperate, high-energy (dynamic) dune fringed coasts and explores the 
limitations and advantages that each technique has, in relation to the presence of vegetation or low texture surfaces.

\section{STUDY AREA}

Five Finger Strand, located on the north coast of County Donegal (NW Ireland), extends approximately for $1.7 \mathrm{~km}$ in a N-S direction between the Five Finger Rock and Lagg Point at the narrow inlet of Trawbreaga Bay (Fig.1). The intertidal zone, around $350 \mathrm{~m}$ wide, is in a modally dissipative (Wright and Short, 1984) and backed by a large vegetated dune system (Jackson et al., 2016) with landforms reaching $25-30 \mathrm{~m}$ in height. Mean spring tidal range is 3.3

$\mathrm{m}$ and semi-diurnal, and the open coast is swell wave-dominated with a modal significant wave height of $2.2 \mathrm{~m}$ and $9 \mathrm{~s}$ wave period. The main wave approach direction is from $\mathrm{W}$ and SW, which are fully refracted within the headlandembayment system. The system, which has been modally-attuned to a large swell wave environment, periodically undergoes significant morphological changes over various spatial and temporal scales that manifest in the development and movements of dynamic nearshore bars and a nearshore ebbtide delta (Cooper et al., 2007; O'Connor et al., 2011). In the past 20 years, the system has experienced an overall shoreline retreat of around $60 \mathrm{~m}$ along the northern part of the beach. As a result, the beach and intertidal area are highly dynamic, with nearshore bars migrating onshore and alongshore at varying temporal and spatial scales in response to modal and high-energy conditions (Jackson et al., 2016). The northern part of the beach presents a mean beach slope of less than $2 \%$ where dunes reach $25 \mathrm{~m}$ height; this situation changes slightly towards the south where the dune field is made up of multiple sand 
ridges of variable height, backed by a dune field of some $10 \mathrm{~m}$ maximum height. The area of interest in this study is in the southern section (see Figs. 1, 2) where a complex dune-beach system with a range of dune topographies and an adjacent sand/cobble beach is located.

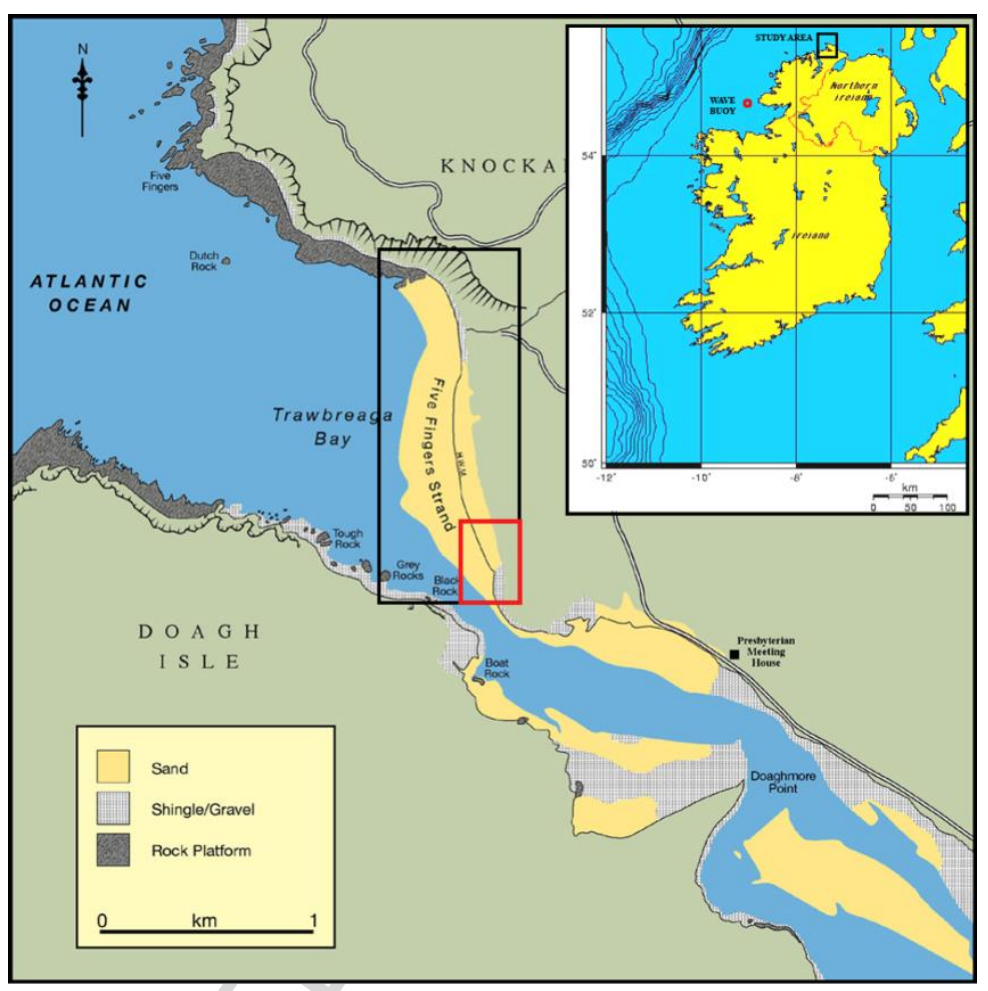

Figure 1: General location map of the study area. Black box shows Five Finger Strand, NW Ireland and the red box highlights the study area.

\section{METHODOLOGY}

\subsection{Data acquisition and processing}

In this study, topographical data was acquired using both a TLS and a SfMUAV to capture the surface of a section of beach and dune morphology. Derived point clouds (PCs) were post-processed to ultimately create associated DEMs from each technique. The vertical, absolute accuracies of the datasets obtained by both TLS and SfM-UAV methods were compared with a Global 
Navigation Satellite System (GNSS) spot point survey (benchmark). Finally, both techniques were compared through the calculation of a DEM of Difference (DoD) for quantification of volumetric, areal and topographic differences and derived implications for coastal geomorphology analysis.

Surveys were undertaken in the southern section of the Five Finger Strand (Fig. 1 red box section and Fig. 2) delimiting a $200 \mathrm{~m} \times 40 \mathrm{~m}$ strip $\left(\approx 8,000 \mathrm{~m}^{2}\right)$. The area of interest is characterised by the presence of a flat beach, gravel ridge and sparse vegetated foredune and more developed and densely vegetated dune ridges inland. Therefore, the study site represents a complex dune-beach transition system offering a range of surface conditions to measure and where to compare these techniques. The survey was conducted during low tide and favourable wind conditions $\left(\sim 5 \mathrm{~ms}^{-1}\right)$ covering the intertidal area (see Fig. 2) up to the bottom dune edge limit (dune toe) and extending landward over a range of beach/dune topographies.

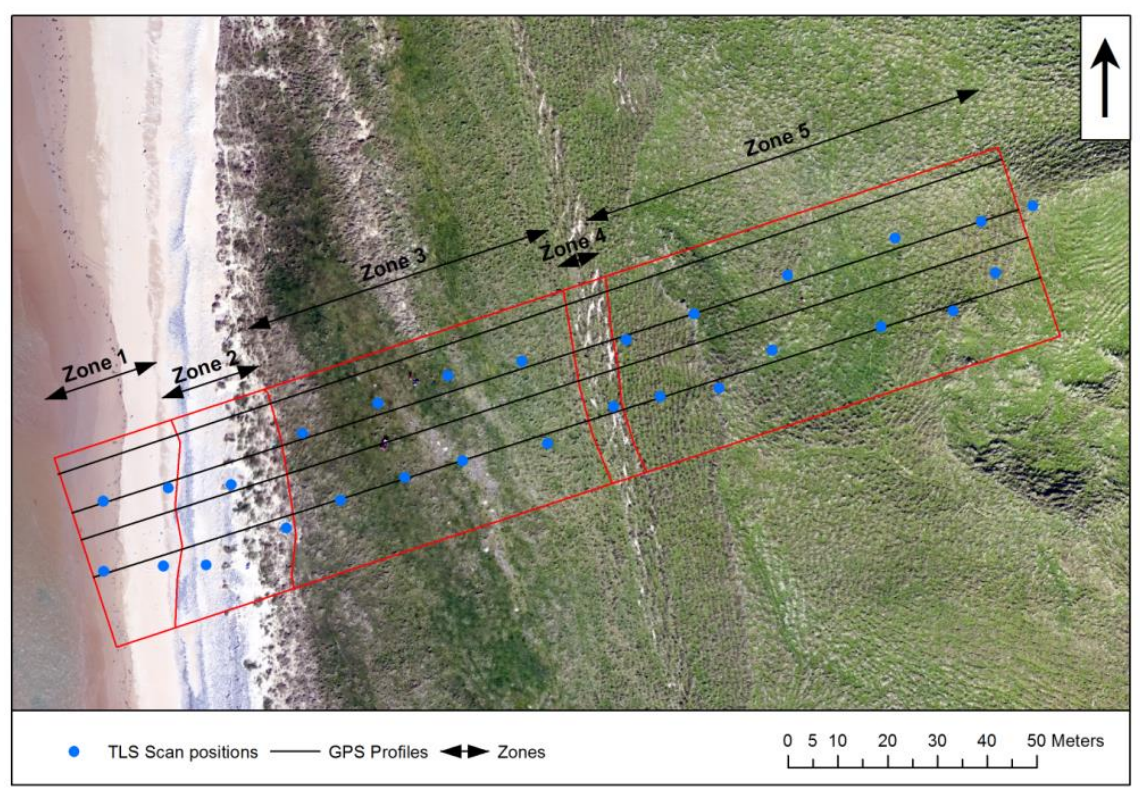


Figure 2: Scheme of scanner locations for the surveys performed. DGPS-derived profiles used as benchmark reference for SfM-UAV and TLS PC comparison and validation of UAV- and TLSderived DEMs. The red boxed section represents the TLS survey area and black dots are the vertical points used for geo-referencing of the TLS point cloud. The orthophoto in the background is derived from the SFM-UAV survey.

\subsubsection{The Terrestrial Laser Scanner: Technical specifications and survey}

The FARO Focus 3D X330 single return laser scanner was set at 1/8 resolution (approximately 11 million points per scan) with a point density of one point every $12 \mathrm{~mm}$ at a distance of $10 \mathrm{~m}$ away from the scanner.

A total of 27 scans station locations were established across the site and divided into 2 rows each approximately $15 \mathrm{~m}$ apart (see Fig. 2) ensuring extensive over-lapping coverage (covering a total linear area of $11,520 \mathrm{~m}^{2}$ ) and reduction of survey shadows in the lee of topographies. Six reference spheres were used as GCPs for each scan. Three of these spheres remained stationary from the previous scan allowing scans to be stitched together using these common spheres. The spheres were surveyed with a RTK dGPS system (Trimble 5800) to a precision level of $0.03 \mathrm{~m}$ in $x, y$ and $z$ for subsequent georeferencing into the Irish National Grid coordinates system (see Fig. 3).

Post-processing for the TLS data included: a) scan registration, b) model georeferencing, c) data filtering, d) vegetation correction, and e) generation of a DEM. Steps a), b) and c) were performed using Faro Scene software where scans were stitched together using overlapping retroflective targets (spheres) 
as shown in Fig. 3. After stitching the scans, the mean target distance error was $0.004 \mathrm{~m}$, however this increased to $0.035 \mathrm{~m}$ when the stitched scans were reprojected onto Irish National Grid Coordinate system using the dGPS locations of spheres at the edges of the study site (due to the error introduced by the GPS). Given the variable point density, resulting from the TLS PC (Table1) a default stray filter was applied to delete outliers and remove vertical anomalies, while a dark scan filter removed less accurate points of low reflectance. Increasing noise with distance from the scanner was limited by applying a $60 \mathrm{~m}$

distance filter to each scan. Since extremely dense point collection was concentrated in the proximity of scanner positions, with density decreasing with the distance from the station position, resampling was conducted to create more uniform densities of points. The TLS PC was therefore resampled to $0.01 \mathrm{~m}$ resolution within Faro Scene to produce a more uniform dataset, particularly in areas close to the scanner where extremely high point densities require considerable processing power. This resulted in a TLS PC of approximately 18.6 million points and a mean point density of 2,326 per $\mathrm{m}^{2}$.

\subsubsection{The SfM-UAV survey: technical specification and survey}

An eBee fixed wing UAV was used in the generation of high-quality aerial surveying and ortho-photography following the SfM approach. The maximum flight duration is 50 minutes and it has a cruise speed of $11-25 \mathrm{~ms}^{-1}$. Emotion software allows automatic generation of a full flight plan, based on GPS waypoints, and calculates the drone's required altitude, displaying its projected trajectory. A RGB 18.2MP camera was used to acquire regular image data in 
the visible spectrum in JPEG format that has a maximum ground resolution of around $0.0275 \mathrm{~m}$ per pixel at $100 \mathrm{~m}$ elevation.

The survey was conducted during favourable weather conditions with a wind speed of approximately $5 \mathrm{~ms}^{-1}$ at an altitude of $115 \mathrm{~m}$ with $70 \%$ forward overlap and $80 \%$ lateral overlap resulting in $0.033 \mathrm{~m}$ pixel size for ground image resolution. A fixed altitude flight was considered adequate as the elevation range was in the region of $30 \mathrm{~m}$. All imagery was collected off-nadir. The UAV ground speed was around $10 \mathrm{~ms}^{-1}$ and the flight took 14 minutes to map the whole coastal-dune system in form of a gridded flight along the southern area. The gridded flight further increased image overlap. The result was a dataset with an average point cloud density of 101 per $\mathrm{m}^{2}$ (808,630 points) from 117 calibrated images (Table 1).

For the SfM-UAV, the post-processing consisted of a) geo-referencing, b) vegetation correction, and c) generation of a DSM and a DEM (Fig. 3). Data were georeferenced using 10 checkerboards targets (GCPs) placed throughout the study area which were also dGPS-fixed and processed through Pix4d Mapper Pro software, resulting in a mean RMS error of $0.021 \mathrm{~m}$. The dGPS used has an overall accuracy of $+/-0.03 \mathrm{~m}$ that propagates into the datasets. The SfM-UAV derived data were processed using Pix4d in which internal and external camera parameters were optimized in order to minimize any vibrations associated with the camera and UAV. This process was followed by a densification of the PC in order to improve the point cloud quality, reduce noise and improve subsequent surface and volume measurements. The resulting PC 
has an average point spacing of $0.13 \mathrm{~m}$ with a more even distribution of points over the study area (i.e. average point spacing among zones range between 0.124 and $0.137 \mathrm{~m}$ ) than the TLS point cloud (Table 1) that resulted in less uniform point spacing between zones.

\section{Table 1}

\subsubsection{The Global Navigation Satellite System (GNSS): the benchmark survey}

An RTK dGPS survey was carried out together with data acquisition by TLS and UAV flight on the $17^{\text {th }}$ of July 2017 . This survey was used as a benchmark and designed to collect 10 checkerboards targets (GCPs) to geo-reference the UAV flight and 8 vertical retroflective targets in the form of spheres (SP) for each scan, which were used to georeference and merge the TLS acquisitions (see Figs. 2, 3). Finally, 1424 surface ground level points along four transects evenly distributed from the intertidal area across the dune extent were collected for calibration and comparison against the TLS and SfM-UAV point clouds. Horizontal coordinates were referenced to Irish National Grid while the vertical values were also corrected to the mean sea level using Malin Head (Ireland) Station. Accuracy for all GPS points was $0.03 \mathrm{~m}$ in the $x, y$ and $z$. 


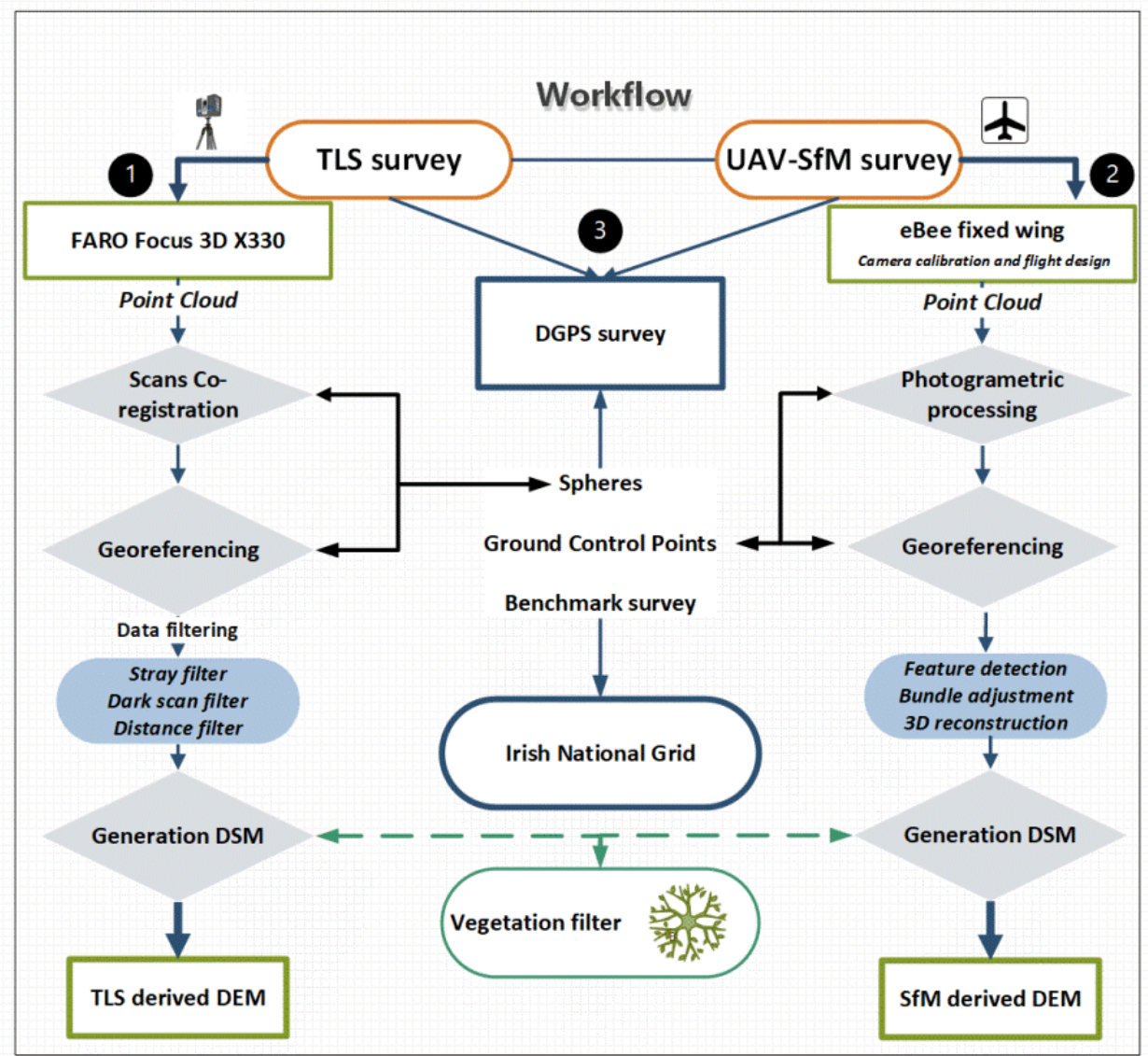

Figure 3: Workflow of methodology for data acquisition where (1) refers to data acquisition and post-processing for TLS, (2) refers to SfM-UAV survey details and post-processing, and (3) represents the GPS survey. Note interactions between benchmark survey (GPS) and TLS and UAV surveys.

\subsubsection{Vegetation correction method}

The separation of ground bare earth and the canopy is an essential part of building accurate DEMs but it can be challenging within densely vegetated areas where laser penetration to the ground surface is not always easily achieved. Using a TLS in a vegetated area could result in the capture of different depths of a canopy depending on the penetration. On the contrary, the UAV only captures what is visible across a surface, either the vegetation surface when it is present or the ground where it is visible. Vegetation elevation 
derived-errors within laser scan data in such areas have been reported previously (e.g. Heritage and Hetherington, 2007). Correction includes the use of a filter based on the selection of the lowest elevation (Smith et al., 2017), the use of GPS ground measurements to optimise window size for point cloud filtering (Guarnieri et al., 2009; Montreuil et al., 2013b), the development of Grid-based lowest Elevation point Filter (Coveney and Fotheringham, 2011) and the use of GPS validation points (Coveney et al., 2010). .

To analyse elevation measurements due to the presence of vegetation five distinct zones across the site (Figs. 2, 4) with different vegetation characteristics were evaluated. Zone 1, the intertidal area and dry beach was characterised by low variation in slope (topographic heights between 1.0 to $2.0 \mathrm{~m}$ ) and the absence of vegetation. Zone 2 was characterised by the presence of a cobble ridge and an incipient foredune (heights from 2.6 to $5.0 \mathrm{~m}$ ) which was partially vegetated with Ammophila sp. Moving landward, Zone 3 was represented by a smooth dune surface with low cover of grass that increased in height towards Zone 4, which had a steep dune ridge (topographic heights 8-12 m). Finally, Zone 5 had a complex densely vegetated dune field (dune topographic heights ranging from 12 to $32 \mathrm{~m}$ ). 

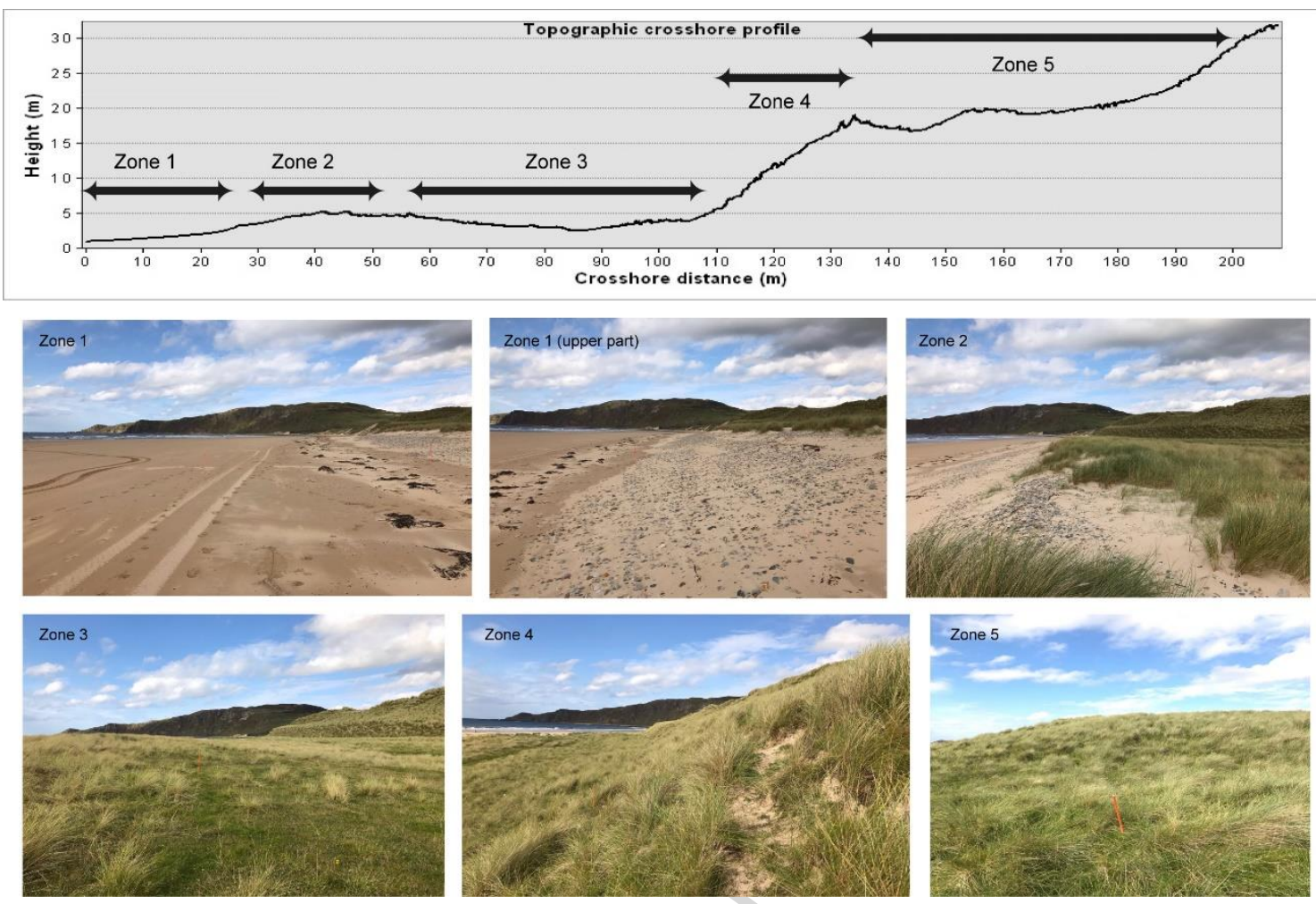

Figure 4: Upper part represents a topographic profile showing boundaries of delimited zones used in the analysis. Below pictorial overview of zones distinguished in the TLS and SFM-UAV comparisons and a representative topographic cross-shore profile of the study area differencing the zones. Zone 1: The beach comprising wet and dry sand. Zone 2: Cobble ridge and foredune area characterised by undulations. Zone 3: Smooth dune surface covered by low vegetation. Zone 4: Dune ridge face. Zone 5: Dense dune vegetation field.

Using the method developed by Montreuil et al. (2013b), vegetation coverage was evaluated from a series of $2 \times 2 \mathrm{~m}$ quadrats by conducting GPS-field measurements at bare-ground level. The first step involved choosing a set of 2 representative quadrats based on vegetation coverage and diversity in each zone where to carry out a 10-point random sampling programme of vegetation height. For each representative quadrat ( 2 per zone) the maximum and mean vegetation height $(\mathrm{m})$ was calculated using the central body of the plant as a reference based on previous sampling program. The second step consisted of 
calculating the maximum $\left(Z m a x_{v e g}\right)$, minimum $\left(Z \min _{v e g}\right)$ and mean $\left(Z m^{2} a_{v e g}\right)$ elevations from the TLS and SfM-UAV PCs using representative cell size windows of $0.1 \mathrm{~m}$, and finally comparing these values against the previous DGPs measurements (see Table 2). Zone 1 was excluded from the analysis given the absence of vegetation.

Table 2

The final step was the generation of DEMs with the purpose of calculating surface volume, areal and topographic variations (DEM of Difference -DoD-) between both surveys. The DoD is frequently used to assess and quantify spatial patterns of geomorphic change through time (Brasington et al., 2003; James et al., 2012). Here, however, we use the DoD as the difference between two datasets gathered by different technologies (TLS vs SfM-UAV) rather than between (temporally) successive surveys. The subtraction of one from the other (e.g. SfM-UAV from TLS) highlights the areas of dominant differences after vegetation correction filter. The Geomorphic Change Detection (GCD) add-in of ArcGIS (Wheaton et al., 2010) was used for quantifying uncertainties independently for each DEM and for propagating them through the DEM of difference. The calculations were ran using a propagated error scheme (based on individual RMS errors, $0.035 \mathrm{~m}$ for TLS and $0.021 \mathrm{~m}$ for the SfM-UAV) which combines the error from TLS and SfM-UAV surfaces into the elevation differences calculations. Results (Figs. 8, 9, results section) are provided with a confidence interval of $95 \%$, which guarantees the accuracy of the results (see Wheaton et al., 2010 for further details on method). 


\section{RESULTS}

\subsection{Spatial analysis of Point Clouds}

By using the closest individual point of each PC to the benchmark survey (planar distance) correlation among TLS, SfM-UAV and ground GPS points is presented in the absence of vegetation error correction. Given the variability of point distribution and density (Table 1) in each PC, the average planar distance of compared pairs varies from $0.09 \mathrm{~m}$ for the GPS-TLS to $0.04 \mathrm{~m}$ for the GPSSfM-UAV.

In general, regression plot lines (Figs. 5a-5e) and histograms of differences (Figs. 5f, g) demonstrate good correlations between GPS field measures and the compared TLS vs SfM-UAV point clouds, thus confirming previous investigations about the general adequacy of these techniques (Mancini et al., 2013; Zhou et al., 2017). Further, the analysis of standardised residuals (ZR) (i.e. a measure of the strength of the difference between the observed and expected value in a regression analysis) was used to assess the linear regression between the GPS ground truth measures and both the TLS and the SfM-UAV surveys (Fig. 5). A symmetric bell-shaped histogram of the residuals indicates that the variance is normally distributed (differences between measured and expected values are small) whereas asymmetric histograms indicates significant differences (location and value of the residuals). 

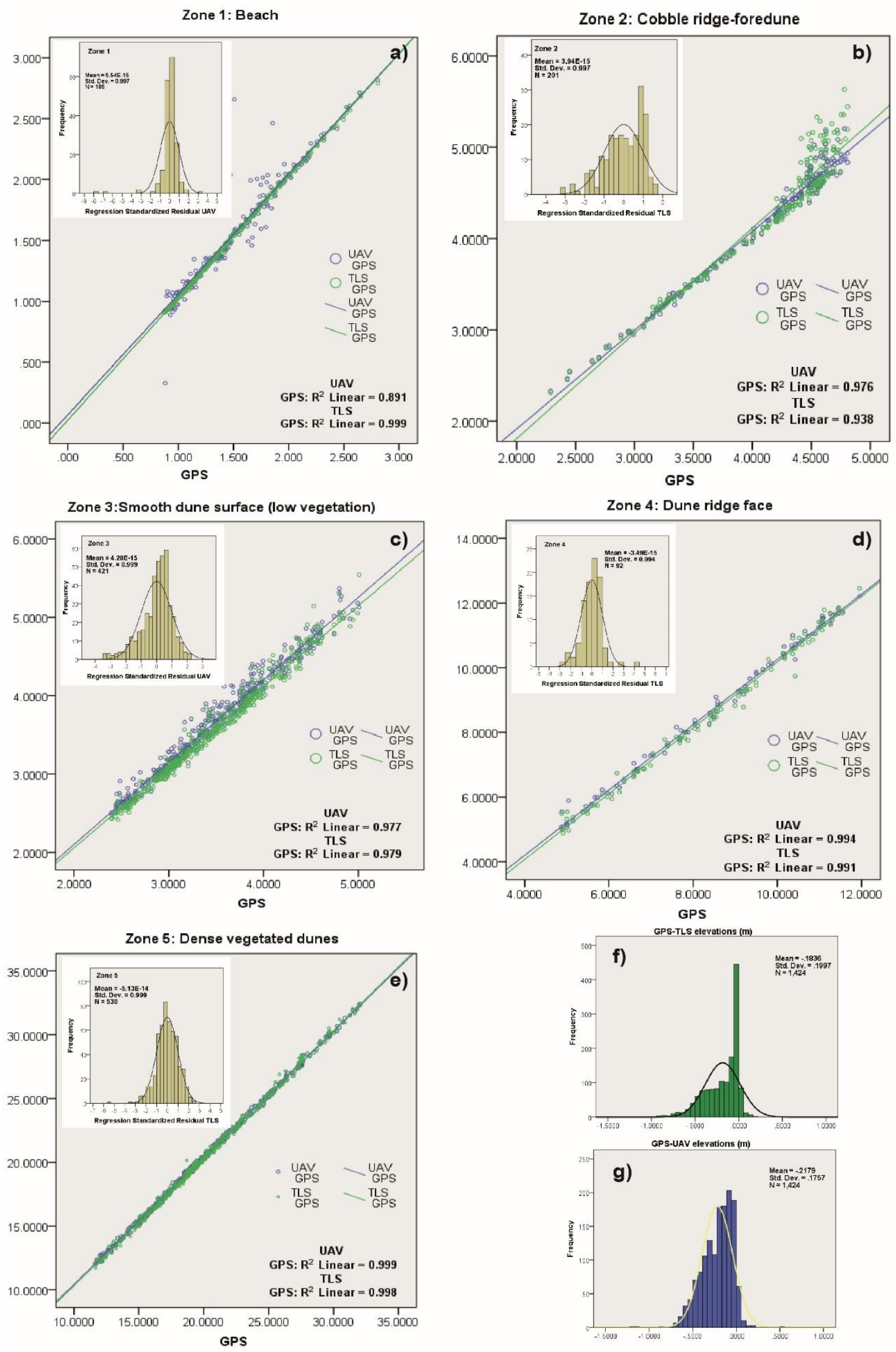
Figure 5: From a) to e): Fit of Linear regression for TLS and SfM-UAV elevations versus the benchmark (GPS) for each of the five zones identified in Fig. 2. Inserts show histograms of regression residuals. f) and g) show frequency histograms of differences for GPS-TLS and GPS versus SfM-UAV respectively.

\section{Table 3}

In Zone 1, the GPS-TLS comparison shows a near 1:1 fit between corresponding points $\left(\mathrm{R}^{2}=0.999, \mathrm{p}<0.05\right)$ with a low dispersion of data (Table 3), whereas for the SfM-UAV, more scattered values are present and a lower correlation is found. The GPS versus SfM-UAV histogram of residuals confirms that significant differences $(-0.5>\mathrm{ZR}<0.5)$ corresponds to points surveyed in extremely flat and higher moisture areas where the SfM-UAV seems to fail.

Moving landward, in Zone 2, the presence of undulations associated with cobble ridges and low, partially vegetated foredunes, results in a better correlation among the GPS and SfM-UAV dataset $\left(R^{2}=0.976, p<0.05\right)$ and lower dispersion compared to GPS values (Table 3, Zone 2). Scattered values for the TLS-GPS comparison corresponds to ZR $>1$ (over $19 \%$ of the values show differences $>0.3 \mathrm{~m}$ ) which are mainly located in vegetation corridors and shadow areas favoured by foredune morphology. Along the smooth dune surface with patches of low vegetation (Zone 3) both the TLS and the SfM-UAV show good correlations with respect to the benchmark $\left(R^{2}=0.97, p<0.05\right)$, however, different patterns in linear distribution of points is evident. The interpretation of the SfM-UAV ZR histogram (Fig. 5, Zone 3) shows that for $13 \%$ of the points, differences between heights are $>0.3 \mathrm{~m}$ that corresponds with the presence of sparse and medium sized vegetation. However, only $5 \%$ of these 
differences account for the TLS PC therefore suggesting that an over-estimation of the SfM-UAV compared to TLS and the benchmark can be expected in this zone.

In Zone 4, scattered values in both linear regressions show the disparity between TLS and SfM-UAV when a trend is not clear. The complex topography, where slopes range from $30 \%$ to $70 \%$, and the presence of dense and vertically developed vegetation, seems to influence the performance of both techniques. Looking in detail at the ZR and the dispersion of the data (Table 3, Zone 4), both the TLS and SfM-UAV over-estimate heights by over $0.3 \mathrm{~m}$ in $25 \%$ of cases. However, for the TLS, points where these differences are shown seem to correspond to abrupt changes in height where survey shadows are likely, whereas for the UAV, those are mainly linked to densely vegetated areas. Finally, in Zone 5 , linear regression again shows a very high $\mathrm{R}^{2}$ correlation despite some points being scattered around the fit line as shown in the residuals histogram for the TLS. The complexity of Zone 5 does not allow favouring one technique over the other. Respectively, $56 \%$ and $61 \%$ of TLS and SfM-UAV points show a difference in height $>0.3 \mathrm{~m}$ compared to the benchmark. In general, in the absence of a vegetation error correction, incidences of greatest differences shown against GPS points corresponds to flatter and densely vegetated areas for the SfM-UAV whilst for TLS it is a combination of slope, vegetation and distance to the scan location (point density and distribution).

\subsection{Vegetation filtering and DEMs generation}


The results of the relationship between measured vegetation heights versus that estimated from SfM-UAV and TLS are summarised in Table 2. Fig. 6A shows a strong correlation $\left(R^{2}>0.99, p<0.05\right)$ between the minimum TLS and $\mathrm{SfM}$ value $\left(\mathrm{Zmin}_{\text {veg }}\right)$ and $Z g p s$ indicating that the minimum value of the PCs data within each quadrat of $2 \times 2 \mathrm{~m}$ could adequately represent the topographic surface for most of the zones. The mean difference between the two values is $<0.3 \mathrm{~m}$ for the TLS and around $0.44 \mathrm{~m}$ for the SfM-UAV. It has to be noted than in all cases, greater values are associated with zones with height vegetation and dense coverage (i.e. zone 4 and 5) indicating reduced laser penetration and derived surface problems for image reconstruction using the SfM-UAV.
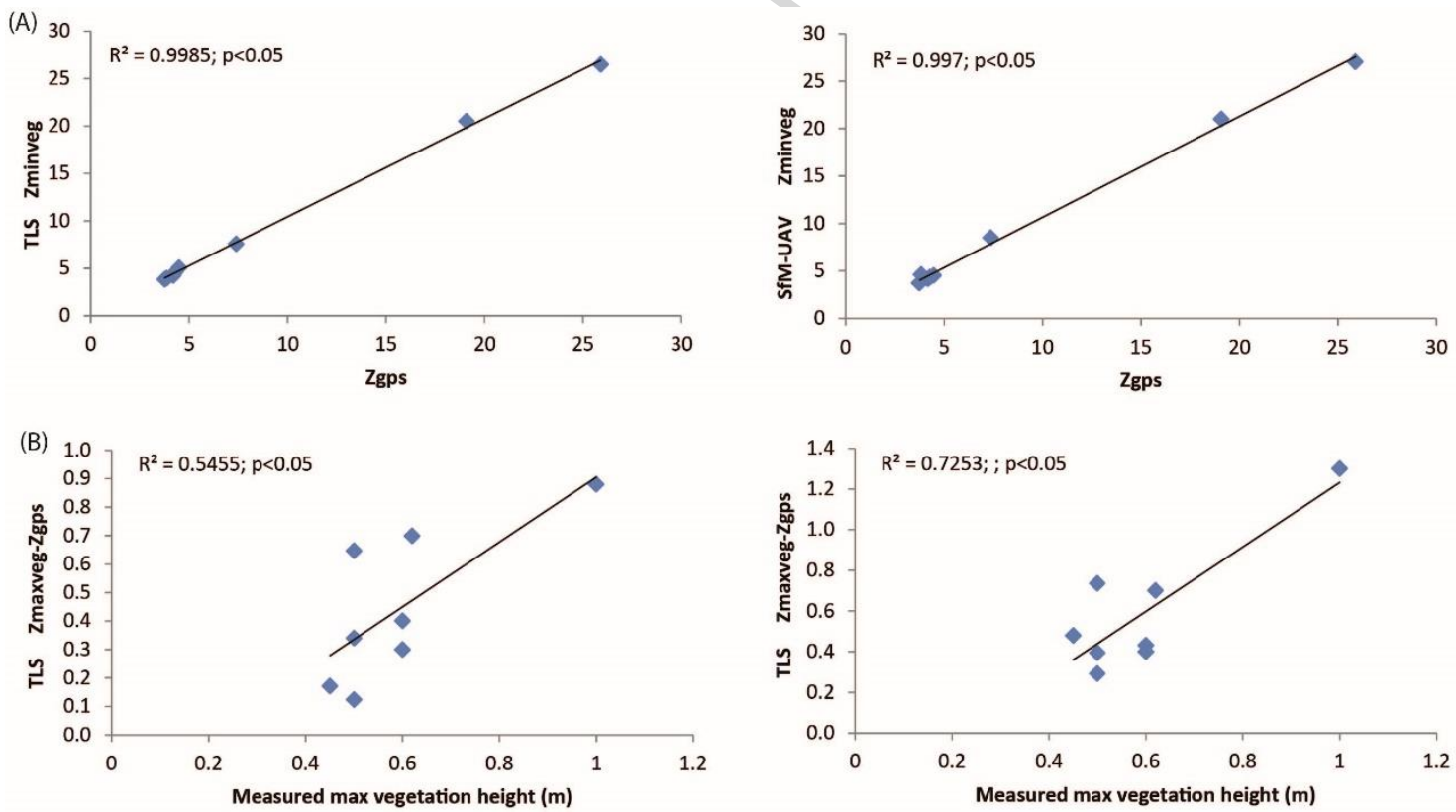

Figure 6: A) Linear correlations between the minimum value of vegetation in each $0.1 \mathrm{~m}$ cell window $\left(\mathrm{Zmin}_{\text {veg }}\right)$ and measured GPS (Zgps) for each of the representative quadrats within each zone. B) Linear correlations between (Zmaxveg-Zgps) and maximum vegetation height measurements $(\mathrm{m})$ for each of the representative quadrats surveyed. 
Similarly, a statistically significant correlation $\left(R^{2}>0.54 ; \quad p<0.05\right)$ between

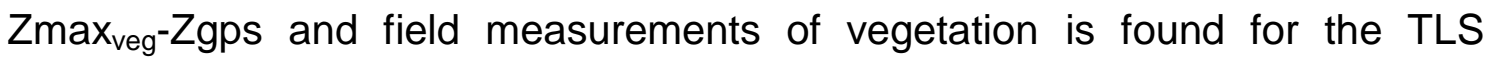
indicating that there are few cases in which it is detecting the top of the vegetation canopy whereas a much strong correlation $\left(R^{2}=0.73\right)$ is found for the SfM-UAV (Fig. 4b) particularly in very dense areas (zones 4, 5). Fig. 6 and Table 2, therefore, verifies that from both technologies the minimum value within each cell size can be used as the best representation of the ground surface, at least for most of the study area. This is in line with previous studies from Coveney and Fotheringham (2011) that indicates that the minimum value within each quadrat could adequately represent the ground if the laser can penetrate the vegetation. In addition, the analysis demonstrated that the GPS field measurements are adequate to validate quantify and filter vegetation from TLS and SfM-UAV PCs prior to retrieving a DEM of the study area.

\subsection{DoD for coastal geomorphic change detection}

For each technique, two DEMs, at 0.2 and $0.5 \mathrm{~m}$ resolutions, were generated using Natural Neighbour binning as an interpolation method and the minimum value within a $0.1 \mathrm{~m}$ cell size to account for vegetation filtering (see Fig. 7). Further, a DoD was performed for the each pair of DEMs. Since the DEM generated from the SfM-UAV is subtracted from the TLS-DEM, spatially positive differences in elevation are represented in blue (SfM-UAV higher than TLS) and negative (SfM-UAV lower than TLS) in red. 

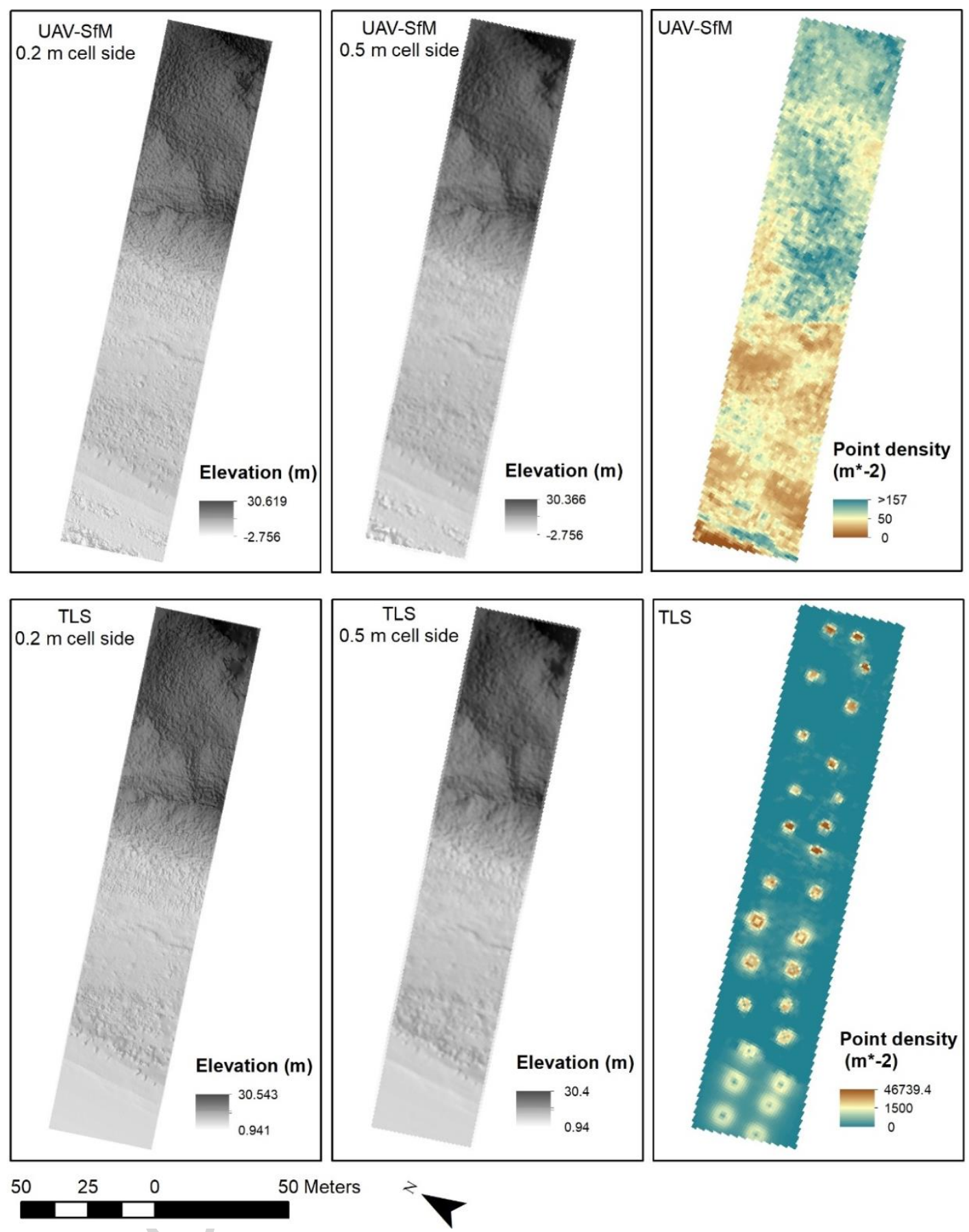

Figure 7: Digital Elevation Models of the study area gridded at $0.2 \mathrm{~m}$ and $0.5 \mathrm{~m}$ cell size. Top section corresponds to SfM-UAV derived DEMs and bottom section corresponds to TLS derived DEMs. Top right and bottom right panels show the point density $\left(\mathrm{m}^{2}\right)$ achieved in each survey.

The comparison between the two DEMs (resolutions of 0.2 and $0.5 \mathrm{~m}$ respectively) shows that, although not very significantly, final DEM resolution 
influences the resulting 3D topographic differences $\left(Z_{\text {diff }}\right)$ as shown in Fig. 8. In this respect, the total area of detectable change (i.e. with a probability greater than the confidence interval) increases from $47 \%$ to $48 \%$ when increasing the cell size leading to a difference of $\pm 300 \mathrm{~m}^{2}$ in areas with negative and positive differences, respectively (Fig. 8B).

Focusing on the $0.2 \mathrm{~m}$ resolution $\mathrm{DEM}$, areas with the highest differences $\left(Z_{\text {diff }}>\right.$ $\pm 0.7 \mathrm{~m}$ ) are concentrated, almost exclusively, along the seaward part of zone 1 corresponding to the wet sandy beach and in the north-eastern corner of zone 5, corresponding to a dense vegetated dune field (Fig 8). Both areas are believed to be subjected to heavy interpolation given the resulting point density and point distribution (Table 1). This leads to the occurrence of occluded areas that forces a rougher interpolation of points thus affecting the SfM-UAV vs TLS comparison.

The detailed analysis of zones 1 to 5 allows a better understanding of local elevation differences occurring between the two overlapping DEMs extracted from the TLS and SfM-UAV. In zones 4 and 5, 63\% of the area presents detectable differences whereas in zones 1 and 3 differences account for $36 \%$ and $29 \%$ of the total area, respectively. This result highlights the assortment of situations (patterns of differences between TLS and SfM-UAV) encountered amongst the zones and indeed across the study area (Fig. 8A).

More pronounced positive elevation differences $\left(Z_{\text {diff }} \approx+0.45 \mathrm{~m}\right)$, representing areas where TLS $<$ SfM-UAV, are concentrated towards the northern part of the 
site (zones 4 and 5) and correspond to densely vegetated areas and steeply sloping relief due to the presence of dune ridges. Conversely, the lowest differences $\left(Z_{\text {diff }} \approx 0.20 \mathrm{~m}\right)$ are found along the southern and northern limits of zone 3 where sparse patches of low to medium vegetation $\left(\operatorname{Zmax}_{\text {veg }}>0.30 \mathrm{~m}\right)$ are present (Fig. 8).

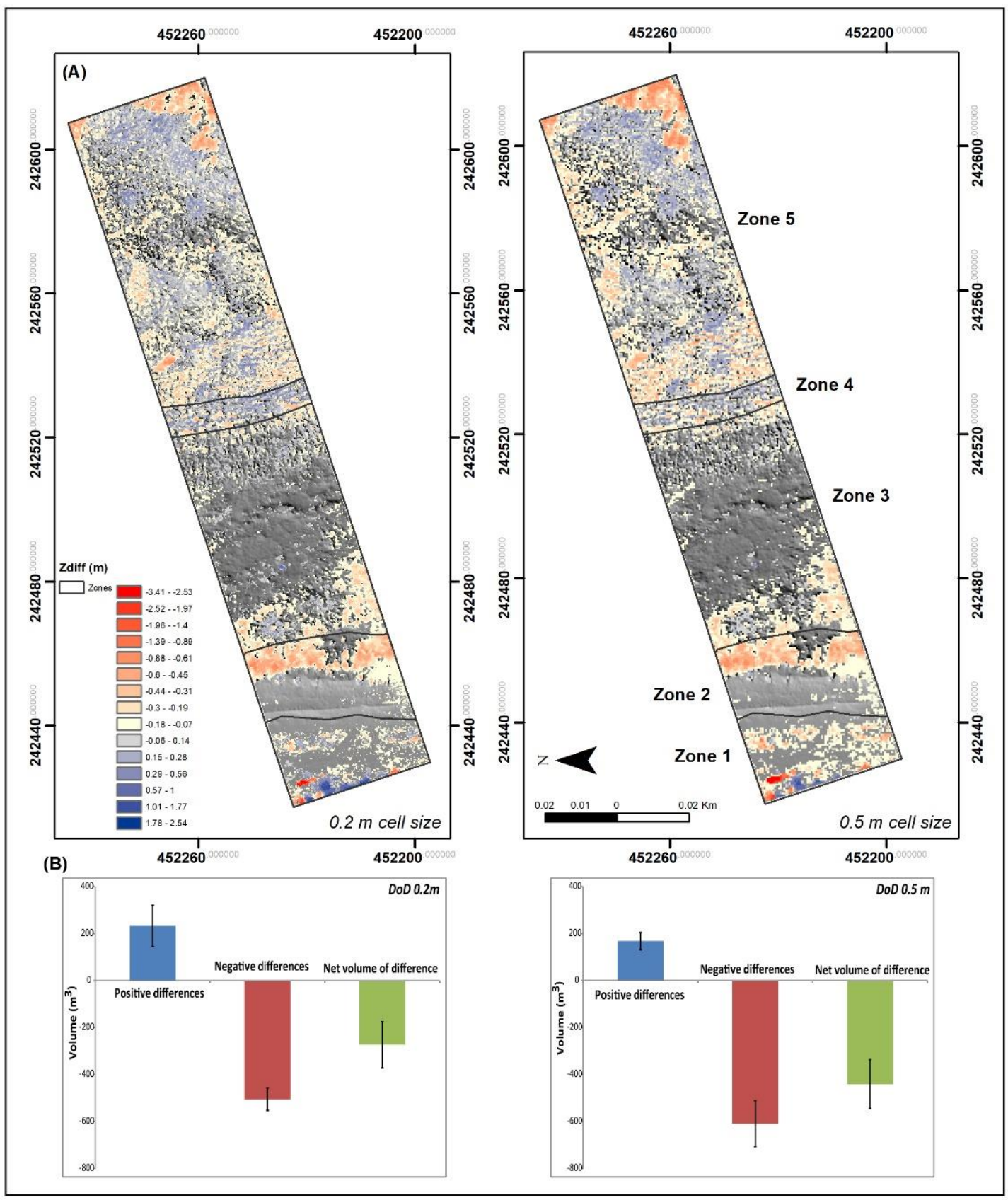


Figure 8: A) Cartography output of DoD showing elevation differences between SfM-UAV and TLS DEMs at $0.2 \mathrm{~m}$ (left) and $0.5 \mathrm{~m}$ cell resolution (right). B) Total 3D volume differences between $0.2 \mathrm{~m}$ (left) and $0.5 \mathrm{~m}$ cell resolution (right) models.

The negative differences shown in red (TLS > SfM-UAV) correspond to zone 2 (and also extend to the limits of zone 3) and zone 5. Significant negative differences are found in Zone 2 which is dominated by the presence of dune ridges and partially vegetated foredunes $\left(Z_{\max } \mathrm{veg}=0.5 \mathrm{~m}\right)$ resulting in abrupt changes in topography (Figs. 4,8 ) and $Z_{\text {diff }}$ ranging from -0.51 to $-0.30 \mathrm{~m}$. These negative differences increase with the distance to TLS scan position (towards the outer edges of the study area). Similarly, across zone 5 , a mixed pattern of negative and positive differences is found with a mean $Z_{\text {diff }} \approx-0.20 \mathrm{~m}$, dominating the outer edges and some patches along the central area. 


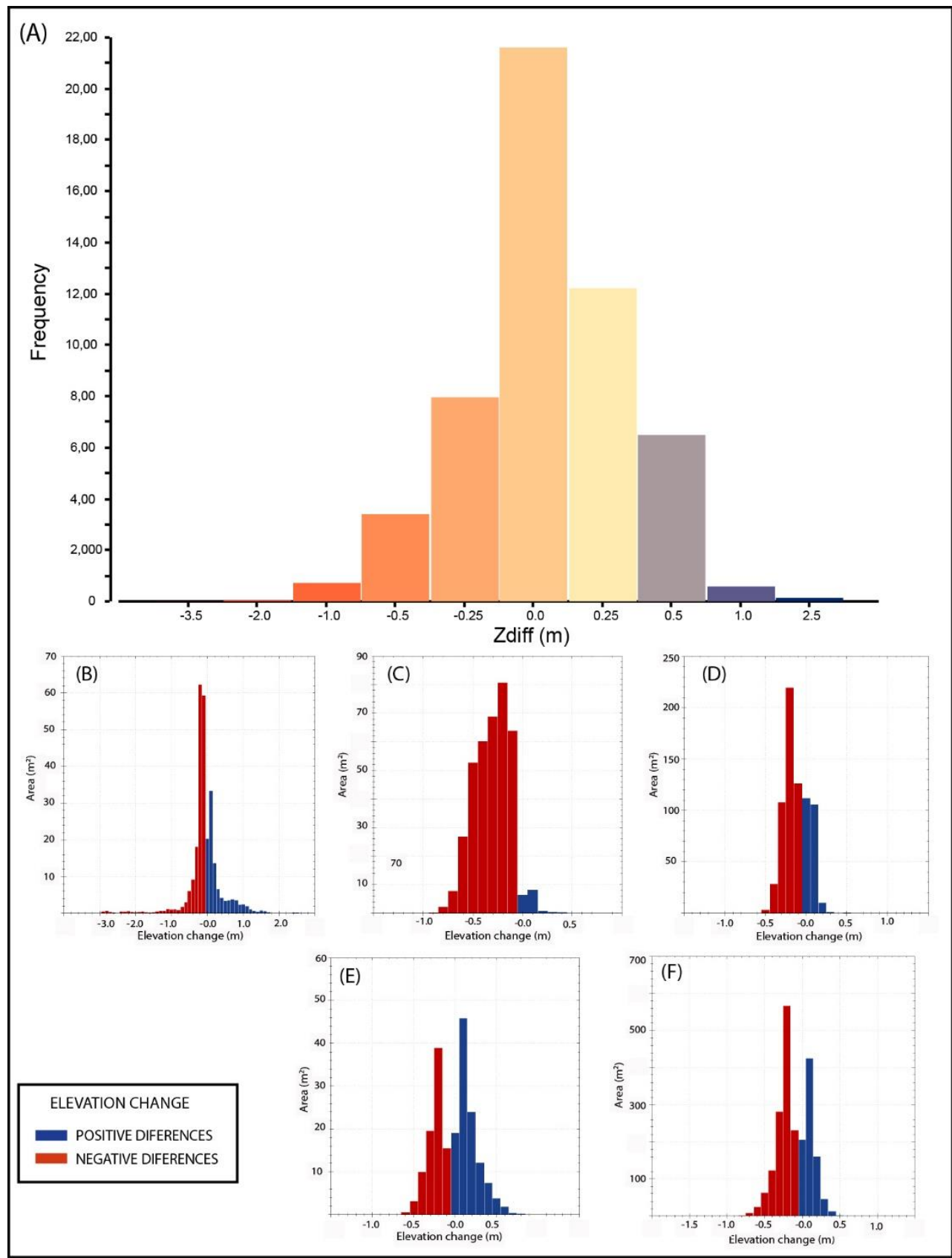

Figure 9: A) Frequency histogram of differences $\left(Z_{\text {diff }}\right)$ for $0.2 \mathrm{~m}$ cell resolution $D E M$ of whole study area. From B) to F) zonal histograms of Zdiff (m) for zones 1 to 5 showing positive and negative elevation changes (in blue and red respectively).

The DoD histogram (Fig. 9A) reveals that $96 \%$ of the differences are in the range -0.5 to $0.5 \mathrm{~m}$ and $64 \%$ between just -0.21 to $0.21 \mathrm{~m}$, suggesting that after vegetation filtering, there are still other variables accounting for differences 
between both techniques. The TLS and SfM-UAV DEM modelled differences follow a quasi-Gaussian distribution, where most of the differences are lower deviations in elevation $\leq \pm 0.7 \mathrm{~m}$ (Fig 9, A) corresponding to the surface of around $3700 \mathrm{~m}^{2}$ (Fig. 8 B). In terms of volumetric differences (on a cell-by-cell basis, the DoD depth multiplied by cell area and summed for those areas), the total volume of difference between both DEMs accounts for $273 \mathrm{~m}^{3}(32 \%$ positive and $68 \%$ negative differences as shown in Fig. $8 \mathrm{~B}$ ).

Closer inspection of the $Z_{\text {diff }}$ frequency distribution of zonal histograms shows that for zone 3 (Fig. 9D), a largely vegetation-free (or very low) ground area,

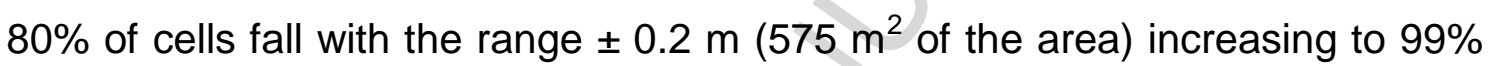
for the range of difference between -0.5 to $0.5 \mathrm{~m}$. On the other hand, across largely vegetated areas such as zones 4 and 5 (Figs. $9 \mathrm{E}, \mathrm{F}$ ), $71 \%$ of the cells are within the range $\pm 0.2 \mathrm{~m}$ corresponding to $144 \mathrm{~m}^{2}$ and $1590 \mathrm{~m}^{2}$ respectively. In these areas, though $97 \%$ of the differences range between $\pm 0.5 \mathrm{~m}$, two thirds of the total surface inspected present positive or negative differences induced by complex topographies (dune crest and slack) and vegetation density.

In zone 1 (Fig. 9 B), only $36 \%$ of the surface depicts detectable change where cells ranging of $\pm 0.2 \mathrm{~m}$ only account for $68 \%$ ( $86 \%$ possess $Z_{\text {diff }}$ of $\pm 0.5 \mathrm{~m}$ ). Given the absence of vegetation in this area, it is suggested that the differences correspond to problems with SfM-UAV effective terrain reconstruction (Westoby et al., 2012). Despite the fact that in zone 2 only $41 \%$ of the total area present detectable differences between the TLS and SfM-UAV DEM models, and mostly 
concentrated in the northern area, it is one of the zones with the largest differences. Accordingly, analysis of the $Z_{\text {diff }}$ histogram reveals that $42 \%$ of cells range $\pm 0.2 \mathrm{~m}$ (Fig. $9 \mathrm{C}$ ) which increases to $89 \%$ for differences between the ranges $\pm 0.5 \mathrm{~m}$, suggesting substantial deviations between the two techniques.

\section{DISCUSSION}

This work examines the use of TLS and SfM-UAV techniques for the optimal acquisition of high-resolution topographic data over certain complex coastal landforms. TLS and SfM-UAV techniques are popular because of their perceived ease of use and high level of automation, as well as their ability to cover large areas rapidly compared to standard topographical GPS surveying. This level of automation, however, does not consider the actual processing involved in the photogrammetric calculations, masking any source errors that finally hampers the accuracy of DSM (James et al., 2017a). Differences between SfM-UAV and TLS approaches are clear when comparing upfront data acquisition times. In this study, the survey with UAV flight took around 14 minutes (plus 30 minutes of surveying the GCP with the GPS) and covered a larger area, while the TLS survey took 5 hours to complete in the field and required extensive manual post-processing. Results support the validation of both the SfM-UAV and TLS techniques in acquiring accurate and precise topographic data of complex coastal systems compared to a traditional topographic survey using GNSS although some limitations are identified. The validation procedure was assessed, on one hand, through comparison of point clouds generated from SfM-UAV and TLS with dGPS ground control points and, 
on the other hand, testing the effect of spatial resolution and the application of vegetation filter was conducted using a DoD approach.

\subsection{Influence of point density and distribution}

Results suggest that the main differences between PCs are strongly related to a point distribution and point density issue (Table 1, Fig. 7). The fact that mean point distance is 0.09 and $0.04 \mathrm{~m}$ for the TLS and SfM-UAV, respectively, to the closest GPS point used in the comparison conducts to worse correlation for the TLS (Fig. 5) in poor density areas due to occlusions and survey shadows (Coveney et al., 2010). This leads to greater elevation differences when compared to either the SfM-UAV PC or the benchmark as there are no points in the cloud directly below to compare to and then the difference in elevation is calculated using the nearest point. This results in an exaggeration of the height difference between surveys. On the other hand, although the SfM-UAV survey had a reduced point density, the actual distribution is uniform across the site, leading to an apparently good agreement within more complex areas.

The second source of discrepancy is related to the un-modelled presence of vegetation, especially in flat or very high roughness areas (i.e. foredunes)

where a combination of low heights and vegetation can lead to laser scan occlusions (Pelletier and Jerolmack, 2014), and difficulties in surface reconstruction for the SfM-UAV (Micheletti et al., 2015a). This can be seen in the residuals, whose greatest differences correspond to vegetated points and ranges from 0.5 to $0.7 \mathrm{~m}$, coincident with the mean height of vegetation existing in these zones. Furthermore, as reported previously by Mancini et al. (2013), 
the different approaches in which ground elevations were acquired (SfM-UAV elevations by image processing, TLS by distance to the laser and the GPS values collected by a hand-held pole) can also affect correlations and histogram results. Nevertheless, both point clouds do show a consistent level of vertical accuracy albeit with local differences depending on the terrain surface (Fig.5). In particular, the SfM-UAV exhibits an almost ideal behaviour in comparison to the GPS points taken over complex topographies such as vegetated dunes and cobble ridges. Conversely, the TLS performs better over the beach surface and relatively flat and low to zero vegetation areas (e.g. Zhou et al., 2017) where final point density is $>3000$ points $/ \mathrm{m}^{2}$ (Table 2).

Results from linear regression plots (Fig. 5) within each zone allow an initial understanding of the main differences between techniques in the absence of vegetation filtering. However, the fact that GPS point distributions were acquired along a cross-shore profile partially coincident with TLS scan positions may have biased TLS points' representation. This is evident in zones 2, 3 and 4 where the residuals correspond with measurements taken in low-density areas (coincident with greater distance from scan position). For instance, across Zone 5 , the complex topography forces the GPS points to be taken closer to the laser scanner positions, favouring good agreement among measures (GPS vs TLS). Therefore, the precision of the TLS with respect to GPS and further SfM-UAV in those areas is highly dependent on the joint impact from the topography (and vegetation) and the distance of the benchmark point to the TLS scan location. Precision reduces with the distance to the scanner and the presence of 
changes in topography as it in itself generates shadows and the vegetation obstructs the laser (Fig 5, c, d, residuals).

\subsection{Influence of vegetation and DEM grid size}

The removal of data points that represent grass, shrubs or any other type of vegetation that may over-estimate the ground surface is important in the bareearth elevation model (DEM) generation (Smith et al., 2017). SfM-UAV and TLS models are equally influenced by the difficulties of occlusion from the presence of vegetation, which in turn affects the resulting surface and topographic reconstruction (Coveney and Fotheringham, 2011; Westoby et al., 2012). Elevation errors within TLS data in densely vegetated areas have been reported to be up to $1 \mathrm{~m}$ (Seymour et al., 2018) and although removal can be achieved through different techniques (Guarnieri et al., 2009; Coveney et al., 2010; Pirotti et al., 2013) optimal results are generally achieved in sparse or vegetation-free areas where laser penetration is much more likely.

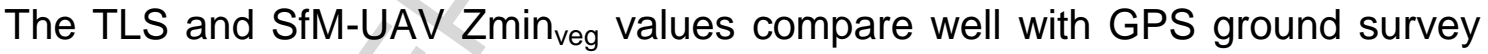
points for most of the quadrats, with mean differences $<0.04$ and $0.06 \mathrm{~m}$, respectively, in flat and sparse to low vegetation areas such as the inter-dune (southern part of zones 2 and 3). This therefore confirms the use of Zmin values as a suitable representation of the ground surface for building DEMs in these terrains and in the absence of airborne multi-return LiDAR (Montreuil et al., 2013b). However, on more complex zones characterised by either the presence of dense vegetation or surface undulations the TLS overestimates heights by up to $0.5 \mathrm{~m}$ (zone 5 and zone 2, foredunes) whilst for the SfM differences can be 
over a meter in zone 5, indicating that the topography of these areas represents the canopy of the vegetation. Furthermore, the fact that the correlation between $Z_{\text {max }}$-Zgps and maximum vegetation measurements is $R^{2}=0.7253(p<0.05)$ is suggesting the SfM-UAV is capturing the surface of the vegetation. On the contrary, this correlation for TLS is smaller $\left(R^{2}=0.54 ; p<0.05\right)$ indicating occlusion in dense vegetated areas that impede the laser to neither reach the ground nor the vegetation canopy.

Given the differences in vegetation height and coverage across the site, a single estimation of vegetation height to be used in the DEM vegetation correction would have introduced a systematic error. However, the use of specific Zmin for $0.1 \mathrm{~m}$ cell size windows ensures that the vegetation correction changes with the terrain and across the DEM. Although this filtering technique has been shown to be more reliable over less vegetated areas (zones 2 and 3 , Table 2) its applicability to densely vegetated areas with multi-layered canopies and complex topographies (zone 4 and zone 5) encountered some limitations. While the TLS and SfM-UAV-derived DEMs were corrected for vegetation, some remaining differences between them are likely to have been caused by the presence of unfiltered dense vegetation (Table 2, Fig. 6) as well as other technical issues discussed below related to survey design and DEM building.

Similarly, the final cell size of the resulting DEM has to accomplish between filtering residual values for vegetation, maintaining a high level of spatial resolution for further coastal modelling (Coveney and Roberts, 2017) and a minimal threshold for vertical change detection (Eltner et al., 2015), particularly 
in their use for post-storm effects in coastal areas. Smith et al. (2017) set the optimal DEM resolution in $0.10 \mathrm{~m}$ planimetric raster size for monitoring a dune blowout, Montreuil et al. (2013b) chose $0.5 \mathrm{~m}$ for a foredune area, whereas Coveney and Fotheringham (2011) uses $1 \mathrm{~m}$ in a salt-marsh environment. Given the average ground point density and the mean size of the vegetation in denser areas, two grids of 0.2 and $0.5 \mathrm{~m}$ planimetric raster size were chosen to overcome the noted vegetation residuals and to maintain resolution fine enough to infer differences between techniques. The DEM decimation although useful for downscaling data while retaining information, implies a loss of topography complexity and accuracy in any final models. As the DEM resolution was reduced, the spatial variations of elevation differences at a finer scale become averaged across larger pixels (Lu et al., 2017) leading to differences in the final balance of volumetric and vertical differences (Fig. 7B). This is particularly evident in complex areas such as zone 3, 4 and 5 due to the roughness effect introduced by larger grid size.

\subsection{Spatial variability across the DEM of Difference}

The main challenge in DoD analysis is to distinguish between actual geomorphic change and survey noise which requires particular approaches to quantify error (Wheaton et al., 2010; Williams, 2012). This error, moreover, varies according to the device used and survey design (James et al., 2017a) and normally arises at areas with high form and surface roughness and sparse survey point densities (Williams, 2012). 
Areas with the highest differences $\left(Z_{\text {diff }}\right)$ were concentrated in the most landward vegetated dune (zone 5) (Figs. 8, 9F) and in the wet part of the foreshore. Resulting differences are based on a comparison of interpolated values, and therefore this is likely to be less reliable within poor density areas where the outcomes of the interpolation can diverge from reality (Mancini et al., 2013). Sandy beaches can be challenging environments for SfM-UAV as bare bodies of sand represent low-coloured variability in RGB images (Seymour et al., 2018), which ultimately affect matching between images and reconstruction of the surface (Eltner et al., 2016; 2017). Differences encountered between the TLS and the SfM-UAV (Fig. 8A) in zone 1 can be explained by the low variation in texture of the imagery, as well as the flatness, that characterises this zone. The acquisition of a larger number of images (and from different angles) to enhance overlapping, as well as from different solar angles to create contrast in this part of the foreshore, may have facilitated the recognition of textures in this zone (Fonstad et al., 2013; Mancini et al., 2013) and thus mitigated derived DEMs errors.

Positive-sign errors or differences between TLS-SfM found in zones 4 and 5 are reflecting the influence of vegetation in laser returns at low incidence angles. Many authors (Rosso et al., 2006; Coveney and Fotheringham, 2011; Zhou et al., 2017) have demonstrated that the ability of the scanner to accurate derive heights in densely vegetated areas and within variable relief, even with filtering techniques applied, is less compared to less or non-vegetated locations. In these densely vegetated areas, low-point densities prevented accurate determination of the ground earth surface as reported in zone 5 and to a lesser 
extent in zone 4 . The results, however, could have been slightly improved by increasing the number of TLS surveys (overlapping of scans) from different angles and positions though it would be more time demanding and postprocessing prevents its use in large areas or rapid survey situations. Similarly, vegetation coverage in these areas (Fig. 8, zone 4 and 5) may complicate image matching and reconstruction for the Structure from Motion approach due to its variable appearance from different viewing angles and movements forced by wind (Eltner et al., 2015). Therefore a high degree of overlap might be required for this type of terrain to assure an accurate reconstruction of the surface and to increase point density and quality (Micheletti et al., 2015a). Moreover, varying camera altitude relative to the ground, normally driven by complex and highly variable topographies (James et al., 2017a) as reported here could have complicated image matching which adds to the problem of feature matching due to the presence of vegetation.

The negative differences where mostly localised in sloping flanks (interdunes of zone 2 and zone 5) in line with previous works by Coveney (2013) in a coastal marsh or Westoby et al. (2012) in a coastal cliff environments. Across the foredune (northern section of zone 2) the oblique data capture geometry of the laser scanning seems to be more sensitive to the sporadic presence of vegetation and surface roughness (significant lateral canopy depth resulting from low incidence angle afforded by a tripod-mounted TLS). The presence of vegetated areas in coastal systems (Guarnieri et al., 2009; Pirotti et al., 2013; Fabbri et al., 2017) therefore requires further improvements in data collection through optimising acquisition geometry, decreasing the survey angle of 
incidence and increasing the number of scans from different positions and thus increasing the probabilities of complete penetration though the canopy. On the contrary, the SfM-UAV performed well in zones with complex topographies as reported here for the foredunes due to images taken from above the surface (nadir flight).

\section{CONCLUSIONS}

TLS and SfM-UAV techniques are popular because of their relative ease of use and high level of automation. This, however, can neglect important technical procedures and workflow involving terrain complexity and result in lower quality

DSMs. Further, given the ease of processing through automated workflows and user-friendly software, the critical analysis and understanding of the source of errors and uncertainties in the data is not always apparent.

Coastal morphological studies have seen a rapid increase in the use of these techniques in recent years, however, most of these have focused on the use of just one method in acquiring surface topopgraphic data or do not consider complex coastal-dune systems especially in temperate regions. Here, our study includes two data acquisition techniques (TLS and SfM-UAV) and extends over the beach-dune continuum (including the beach, the transitional foredune and the fully developed dune field) and therefore incorporates a good range of textures, environments and morphologies to help test the applicability of both techniques between each other and over particular surface changes. 
In this study, we carried out a conventional coastal survey following best practices reported in the literature, concerning errors and their mitigation for topographic surveys, using both TLS and the SfM-UAV, to create optimal DEMs using the best possible analysis for each sensor and analytical procedure. We demonstrate that final DEMs are a product of the type of coastal environment being surveyed and the surface features present. In the SfM-UAV survey, technical and environmental aspects such as the varying camera altitude and derived feature matching issues, the presence of vegetation and difficulties for surface recognition from above as well as image reconstruction problems due to low contrast patches of light sand are believed to have had an influence of the final DEM produced. Similarly, in the TLS survey, high incidence angles and the presence of vegetation both in flat and undulated zones resulted in occlusion of laser penetration, which likely propagated to the DEM generation. Although, these artefacts are believed to produce uncertainties in the comparison analysis reported here (and in the differences encountered in the vegetated dune field, the foredune and to a lesser extent the foreshore), we agree with Seymour et al. (2018) that some of them are still difficult to predict or avoid in temperate and complex coastal areas and further research is needed.

1. Our results suggest that both the TLS and SfM-UAV survey methods are in general good tools to derive topographic information in beach/dune systems although some discrepancies within particular terrain types arise. Total survey time required for each shows that surveys using an UAV are faster to implement over TLS surveys but the lower quality of 
surface models generated over flatter terrain using SfM-UAVs needs to be considered.

2. Differences among TLS and SfM-UAV derived surface morphologies are largely insignificant in mild-slope terrains or in the absence of vegetation whereas in complex vegetated areas they can vary greatly suggesting that a combination of environmental and technical factors and not a function of a unique variable are responsible.

3. Temporal comparisons of DEM of Differences (DoDs) created from TLS surveys and then subsequently from SfM-UAV are not recommended as local variations from surface reconstruction, laser penetration and point density as well as seasonal changes in vegetation may lead to misinterpretation of morphological changes.

4. In general, TLS surveys produce more realistic surface models across beach and sparsely vegetated (back beach) areas. SfM-UAV-derived surfaces are poorer representations of the morphology under patchy, moist flat sandy and low texture surfaces. In both cases, survey shadows and errors increased as vegetation density increased although SfM-UAVderived surfaces showed better than expected performance in sparse vegetated and relief areas (foredunes) given that data acquisition is performed using a nadir-view.

5. Our results show for the first time, that beach and dune monitoring requiring high precision using TLS and/or UAVs should be cognisant of local terrain type and vegetation densities, as well as derived artefacts before embarking on survey deployment design and subsequent 3D surface derivation and comparisons. 
6. Our study demonstrates a clear advantage in data acquisition of the SfMUAVs over TLS for surveying surface morphological changes (e.g. from storm wave erosion) because of rapid survey time and ease of deployment, particularly along long stretches of coastal foredunes. 


\section{TABLES}

Table 1. Resulting variability in point density $\left(\mathrm{m}^{2}\right)$, average point spacing $(\mathrm{m})$ across the zones for both Point Clouds. Note the uneven distribution of points influenced by terrain characteristics particularly in the TLS with an average point spacing increasing towards zone 5 , whereas for the SfM-UAV average point spacing does not change significantly.

\begin{tabular}{|c|c|c|c|c|c|c|}
\hline & \multicolumn{2}{|c|}{ Number of points } & \multicolumn{2}{|c|}{$\begin{array}{c}\text { Average Point Spacing } \\
\text { (m) }\end{array}$} & \multicolumn{2}{|c|}{ Point Density per $\mathbf{m}^{2}$} \\
\hline & SfM-UAV & TLS & SfM-UAV & TLS & SfM-UAV & TLS \\
\hline Zone 1 & 69317 & 3599276 & 0.131 & 0.018 & 89 & 4597 \\
\hline Zone 2 & 78707 & 2808192 & 0.124 & 0.021 & 85 & 3049 \\
\hline Zone 3 & 231361 & 6523969 & 0.13 & 0.025 & 92 & 2591 \\
\hline Zone 4 & 36272 & 792675 & 0.137 & 0.029 & 114 & 2493 \\
\hline Zone 5 & 391273 & 4883803 & 0.124 & 0.034 & 113 & 1412 \\
\hline Study Area & 806930 & 18607915 & 0.13 & 0.025 & 101 & 2326 \\
\hline
\end{tabular}


Table 2. Summary of measured vegetation (Zgps) versus Maximum ( $\left.Z_{m a x} x_{v e g}\right)$ and mean $\left.\left(Z_{m e a n}\right)_{\text {veg }}\right)$ estimated vegetation height for the study area. Note that two quadrats are studied in each area and results are presented for both the TLS and the SfM-UAV PCs.

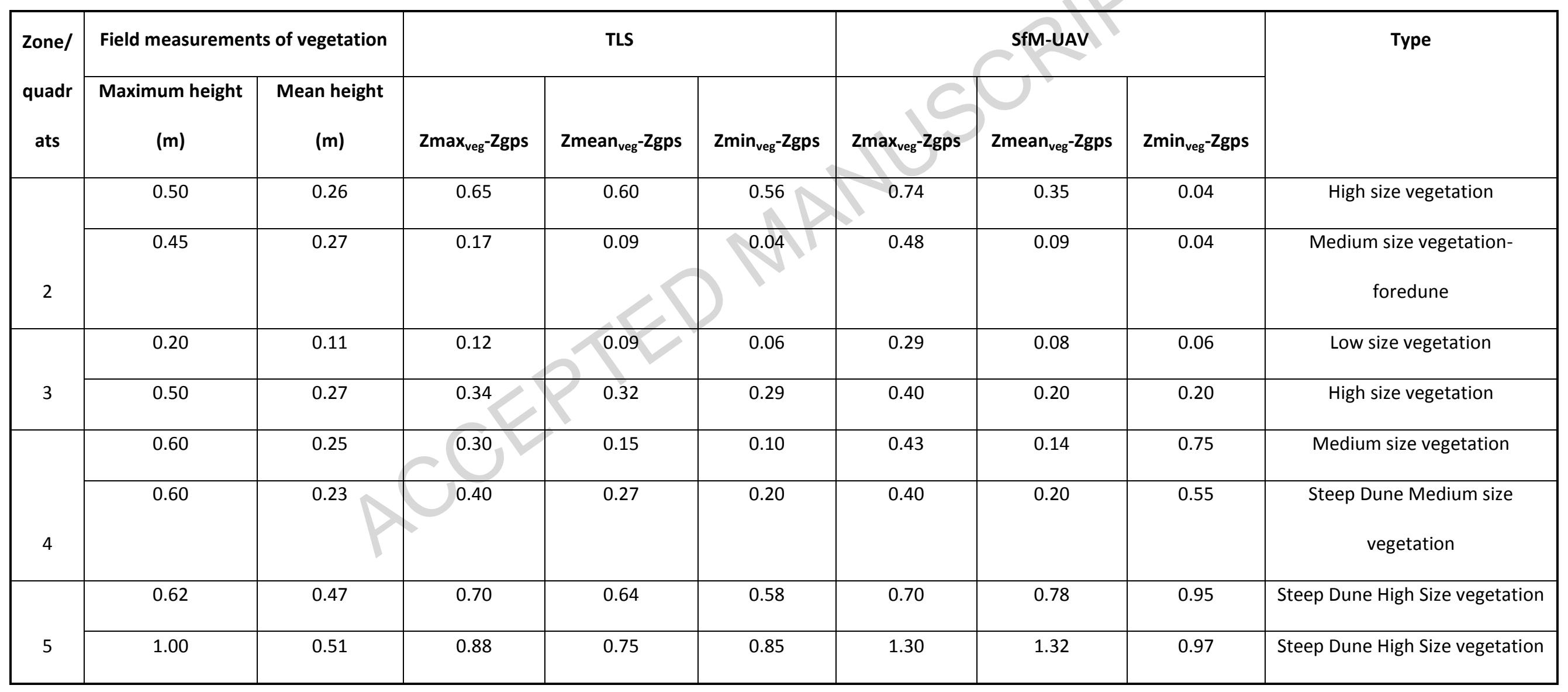


Table 3. Main statistics from Point Cloud correlation analysis between GPS and both the TLS and SfM-UAV at each zone. Note: mean values $(\bar{x})$, range $(R G)$ and standard deviation $(\partial)$.

\begin{tabular}{|c|c|c|c|c|c|c|c|c|c|c|c|c|c|c|c|}
\hline & \multicolumn{3}{|c|}{ Zone 1 } & \multicolumn{3}{c|}{ Zone 2 } & \multicolumn{3}{c|}{ Zone 3 } & \multicolumn{3}{c|}{ Zone 4 } & \multicolumn{3}{c|}{ Zone 5 } \\
\cline { 2 - 13 } & $\bar{x}$ & $R G$ & $\partial$ & $\bar{x}$ & $R G$ & $\partial$ & $\bar{x}$ & $R G$ & $\partial$ & $\bar{x}$ & $R G$ & $\partial$ & $\bar{x}$ & $R G$ & $\partial$ \\
\hline GPS & 1.54 & 1.94 & 1.54 & 4.1 & 2.52 & 0.59 & 3.49 & 2.6 & 0.6 & 8.4 & 7.0 & 2.1 & 19.9 & 20.4 & 4.3 \\
& & & & 1 & & & & 1 & 2 & 3 & 8 & 0 & 9 & 2 & 6 \\
\hline TLS & 1.57 & 1.89 & 1.57 & 4.2 & 3.32 & 0.70 & 3.59 & 3.1 & 0.6 & 8.5 & 7.5 & 2.1 & 20.3 & 20.7 & 4.3 \\
& & & & 4 & & & & 3 & 7 & 8 & 7 & 5 & 2 & 4 & 7 \\
\hline SfM- & 1.59 & 2.49 & 1.59 & 4.1 & 2.88 & 0.64 & 3.67 & 2.8 & 0.6 & 8.6 & 7.2 & 2.1 & 20.3 & 20.4 & 4.3 \\
UAV & & & & 9 & & & & 9 & 6 & 7 & 2 & 3 & 4 & 2 & 4 \\
\hline
\end{tabular}




\section{ACKNOWLEDGEMENTS}

This research was funded by the Juan de la Cierva Program Fellowship Grant (IJCl-2014-20056) from Spanish National Ministry of Ministry of Economy, Industry and Competitiveness and Ulster University. We also want to thank Peter Devlin as well as Carl and Mathieu for their fieldwork assistance. This work is a contribution to the Natural Environment Research Council grant NE/F019483/1. 


\section{REFERENCES}

Abellán, A., Jaboyedoff, M., Oppikofer, T., Vilaplana, J. M., 2009. Detection of millimetric deformation using a terrestrial laser scanner: experiment and application to a rockfall event. Natural Hazards Earth Systems Sci. 9 (2), 365-372.

Baddock, M. C., Nield, J. M., Wiggs, G. F. S., 2017. Early-stage aeolian protodunes: Bedform development and sand transport dynamics. Earth Surface Processes and Landforms 43, 339-346. doi: 10.1002/esp.4242.

Baltensweiler, A., Walthert, L., Ginzler, C., Sutter, F., Purves, R. S., Hanewinkel, M., 2017. Terrestrial laser scanning improves digital elevation models and topsoil $\mathrm{pH}$ modelling in regions with complex topography and dense vegetation. Environmental Modelling \& Software 95, 13-21.

Bater, C. W., Coops, N. C., 2009. Evaluating error associated with lidar-derived DEM interpolation. Computers \& Geosciences 35 (2), 289-300.

Bechet, J., Duc, J., Loye, A., Jaboyedoff, M., Mathys, N., Malet, J. P., Klotz, S., Le Bouteiller, C., Rudaz, B., Travelletti, J., 2016. Detection of seasonal cycles of erosion processes in a black marl gully from a time series of high-resolution digital elevation models (DEMs). Earth Surface Dynamics 4 (4), 781-798.

Brasington, J., Langham, J., Rumsby, B., 2003. Methodological sensitivity of morphometric estimates of coarse fluvial sediment transport. Geomorphology 53 (3), 299-316.

Carbonneau, P. E., Dietrich, J. T., 2017. Cost-effective non-metric photogrammetry from consumer-grades UAS: implications for direct georeferencing of structure from motion photogrammetry. Earth Surface Processes and Landforms 42 (3), 473-486.

Casella, E., Rovere, A., Pedroncini, A., Stark, C. P., Casella, M., Ferrari, M., Firpo, M., 2016. Drones as tools for monitoring beach topography changes in the Ligurian Sea (NW Mediterranean). Geo-Marine Letters 36 (2), 151-163 . https://doi.org/10.1007/s00367016-0435-9

Carter, R. W. G., 1988. Coastal Environments: London, Academic Press, p. 99-149.

Chandler, J., 1999. Effective application of automated digital photogrammetry for geomorphological research. Earth Surface Processes and Landforms 24 (1), 51-63.

Chandler, J. H., Cooper, M. A. R., Robson, S., 1989. Analytical Aspects of Small Format Surveys Using Oblique Aerial Photographs. The Journal of Photographic Science 37 (6), 235240.

Chisholm, N. W. T., 1977. Photogrammetry for cooling tower shape surveys. The Photogrammetric Record 9 (50), 173-191.

Cooper, J. A. G., McKenna, J., Jackson, D. W. T., O'Connor, M., 2007. Mesoscale coastal behavior related to morphological self-adjustment. Geology 35 (2), 187-190.

Coveney, S., 2013. Association of elevation error with surface type, vegetation class and data origin in discrete-returns airborne LiDAR. International Journal of Geographical Information Science 27 (3), 467-483.

Coveney, S., Stewart Fotheringham, A., Charlton, M., McCarthy, T., 2010. Dual-scale validation of a medium-resolution coastal DEM with terrestrial LiDAR DSM and GPS. Computers \& Geosciences 36 (4), 489-499.

Coveney, S., Fotheringham, S., 2011. Terrestrial laser scan error in the presence of dense ground vegetation. The Photogrammetric Record 26 (135), 307-324.

Coveney, S., Roberts, K., 2017. Lightweight UAV digital elevation models and orthoimagery for environmental applications: data accuracy evaluation and potential for river flood risk modelling. International Journal of Remote Sensing 38 (8-10), 3159-3180.

Eltner, A., Schneider, D., 2015. Analysis of Different Methods for 3D Reconstruction of Natural Surfaces from Parallel-Axes UAV Images. The Photogrammetric Record 30 (151), 279299. 
Eltner, A., Baumgart, P., Maas, H.-G., Faust, D., 2015. Multi-temporal UAV data for automatic measurement of rill and interrill erosion on loess soil. Earth Surface Processes and Landforms 40 (6), 741-755.

Eltner, A., Kaiser, A., Castillo, C., Rock, G., Neugirg, F., Abellán, A., 2016. Image-based surface reconstruction in geomorphometry- merits, limits and developments. Earth Surface Dynamics 4 (2), 359-389.

Eltner, A., Kaiser, A., Abellan, A., Schindewolf, M., 2017. Time lapse structure-from-motion photogrammetry for continuous geomorphic monitoring. Earth Surface Processes and Landforms 42 (14), 2240-2253.

Evans, I. S., Dikau, R., Tokunaga, E., Ohmori, H., Hirano, M., 2003. Concepts and Modelling in Geomorphology: International perspectives, Tokyo, TERRAPUB, 253 p.

Fabbri, S., Giambastiani, B. M. S., Sistilli, F., Scarelli, F., Gabbianelli, G., 2017. Geomorphological analysis and classification of foredune ridges based on Terrestrial Laser Scanning (TLS) technology. Geomorphology 295, 436-451.

Fonstad, M. A., Dietrich, J. T., Courville, B. C., Jensen, J. L., Carbonneau, P. E., 2013. Topographic structure from motion: a new development in photogrammetric measurement. Earth Surface Processes and Landforms 38 (4), 421-430.

French, J., Burningham, H., 2009. Coastal geomorphology: trends and challenges: Progress in Physical Geography. Earth and Environment 33 (1), 117-129.

Gienko, G., Terry, J., 2014. Three-dimensional modeling of coastal boulders using multi-view image measurements. Earth Surface Processes and Landforms 39 (7), 853-864.

Gómez-Gutiérrez, Á., de Sanjosé-Blasco, J., Lozano-Parra, J., Berenguer-Sempere, F., de MatíasBejarano, J., 2015. Does HDR Pre-Processing Improve the Accuracy of 3D Models Obtained by Means of two Conventional SfM-MVS Software Packages? The Case of the Corral del Veleta Rock Glacier. Remote Sensing 7 (8), 10269-10294.

Guarnieri, A., Vettore, A., Pirotti, F., Menenti, M., Marani, M., 2009. Retrieval of small-relief marsh morphology from Terrestrial Laser Scanner, optimal spatial filtering, and laser return intensity. Geomorphology 113 (1), 12-20.

Guisado-Pintado, E., Jackson, D. W. T., 2018. Multi-scale variability of storm Ophelia 2017: The importance of synchronised environmental variables in coastal impact. Science of The Total Environment 630, 287-301.

Hancock, G. R., 2006. The impact of different gridding methods on catchment geomorphology and soil erosion over long timescales using a landscape evolution model. Earth Surface Processes and Landforms 31 (8), 1035-1050.

Harwin, S., Lucieer, A., 2012. Assessing the Accuracy of Georeferenced Point Clouds Produced via Multi-View Stereopsis from Unmanned Aerial Vehicle (UAV) Imagery. Remote Sensing 4 (6), 1573-1599.

Hengl, T., Reuter, H. I., 2008. Geomorphometry: Concepts, Software, Applications, Amsterdam, Elsevier, 772 p.

Heritage, G., and Hetherington, D., 2007. Towards a protocol for laser scanning in fluvial geomorphology. Earth Surface Processes and Landforms 32 (1), 66-74.

Hilker, T., van Leeuwen, M., Coops, N. C., Wulder, M. A., Newnham, G. J., Jupp, D. L. B., and Culvenor, D. S., 2010. Comparing canopy metrics derived from terrestrial and airborne laser scanning in a Douglas-fir dominated forest stand. Trees 24 (5), 819-832.

Jackson, D. W. T., Cooper, J. A. G., O'Connor, M., Guisado-Pintado, E., Loureiro, C., Anfuso, G., 2016. Field measurements of intertidal bar evolution on a high-energy beach system. Earth Surface Processes and Landforms 41 (8), 1107-1114.

James, L. A., Hodgson, M. E., Ghoshal, S., Latiolais, M. M., 2012. Geomorphic change detection using historic maps and DEM differencing: The temporal dimension of geospatial analysis. Geomorphology 137 (1), 181-198. 
James, M. R., Robson, S., 2012. Straightforward reconstruction of 3D surfaces and topography with a camera: Accuracy and geoscience application. Journal of Geophysical Research, 117, F03017. doi: 10.1029/2011JF002289.

James, M. R., Robson, S., d'Oleire-Oltmanns, S., Niethammer, U., 2017a. Optimising UAV topographic surveys processed with structure-from-motion: Ground control quality, quantity and bundle adjustment. Geomorphology 280, 51-66.

James, M. R., Robson, S., Smith, M. W., 2017b. 3-D uncertainty-based topographic change detection with structure-from-motion photogrammetry: precision maps for ground control and directly georeferenced surveys. Earth Surface Processes and Landforms 42 (12), 1769-1788.

Lane, S. N., 2000. The Measurement of River Channel Morphology Using Digital Photogrammetry. The Photogrammetric Record 16 (96), 937-961.

Lane, S. N., Richards, K. S., and Chandler, J. H., 1994. Developments in monitoring and modelling small-scale river bed topography. Earth Surface Processes and Landforms 19 (4), 349-368.

Lane, S. N., Chandler, J. H., 2003. Editorial: the generation of high quality topographic data for hydrology and geomorphology: new data sources, new applications and new problems. Earth Surface Processes and Landforms 28 (3), 229-230.

Lecours, V., Lucieer, V., Dolan, M., Micallef, A., 2015. An ocean of possibilities: applications and challenges of marine geomorphometry: Geomorphometry for geosciences, International Society for Geomorphometry, Poznan, Poland, p. 23-26.

Lecours, V., Dolan, M. F. J., Micallef, A., Lucieer, V. L., 2016. A review of marine geomorphometry, the quantitative study of the seafloor. Hydrol. Earth Syst. Sci. 20 88), 3207-3244.

Li, Z., Zhu, C., Gold, C., 2004. Digital terrain modeling: principles and methodology. Boca Raton (Florida), CRC press, $319 \mathrm{p}$.

Lu, X., Li, Y., Washington-Allen, R. A., Li, Y., Li, H., Hu, Q., 2017. The effect of grid size on the quantification of erosion, deposition, and rill network. International Soil and Water Conservation Research 5 (3), 241-251.

Mancini, F., Dubbini, M., Gattelli, M., Stecchi, F., Fabbri, S., and Gabbianelli, G., 2013. Using Unmanned Aerial Vehicles (UAV) for High-Resolution Reconstruction of Topography: The Structure from Motion Approach on Coastal Environments. Remote Sensing 5 (12), 6880-6898.

Medjkane, M., Maquaire, O., Costa, S. Roulland, Th., Letortu, P., Fauchard, C., Antoine, R., Davidson, R. 2018. High-resolution monitoring of complex coastal morphology changes: cross-efficiency of SfM and TLS-based survey (Vaches-Noires cliffs, Normandy, France). Landslides 15 (6), 1097-1108. https://doi.org/10.1007/s10346017-0942-4.

Micheletti, N., Chandler, J. H., Lane, S. N., 2015a. Investigating the geomorphological potential of freely available and accessible structure-from-motion photogrammetry using a smartphone. Earth Surface Processes and Landforms 40 (4), 473-486.

Micheletti, N., Chandler, J. H., Lane, S. N., 2015b. Structure from motion (SfM) photogrammetry, in Clarke, L. E., and Nield, J. M., eds., Geomorphological Techniques (Online Edition). London, British Society for Geomorphology.

Montreuil, A.-L., Bullard, J., Chandler, J., 2013a. Detecting Seasonal Variations in Embryo Dune Morphology Using a Terrestrial Laser Scanner. Journal of Coastal Research 65 (2), 1313-1318.

Montreuil, A. L., Bullard, J. E., Chandler, J. H., Millett, J., 2013b. Decadal and seasonal development of embryo dunes on an accreting macrotidal beach: North Lincolnshire, UK. Earth Surface Processes and Landforms 38 (15), 1851-1868. 
Nield, J. M., Wiggs, G. F. S., 2011. The application of terrestrial laser scanning to aeolian saltation cloud measurement and its response to changing surface moisture. Earth Surface Processes and Landforms 36 (2), 273-278.

Nield, J. M., Wiggs, G. F. S., Squirrell, R. S., 2011. Aeolian sand strip mobility and protodune development on a drying beach: examining surface moisture and surface roughness patterns measured by terrestrial laser scanning. Earth Surface Processes and Landforms 36 (4), 513-522.

O'Connor, M. C., Cooper, J. A. G., Jackson, D. W. T., 2011. Decadal Behavior of Tidal InletAssociated Beach Systems, Northwest Ireland, in Relation to Climate Forcing. Journal of Sedimentary Research 81 (1), 38-51.

O'Connor, J., Smith, M. J., James, M. R., 2017. Cameras and settings for aerial surveys in the geosciences:Optimising image data. Progress in Physical Geography: Earth and Environment 41 (3), 325-344.

Pelletier, J. D., Jerolmack, D. J., 2014. Multiscale bed form interactions and their implications for the abruptness and stability of the downwind dune field margin at White Sands, New Mexico, USA. Journal of Geophysical Research: Earth Surface 119 (11), 2396-2411.

Pietro, L. S., O'Neal, M. A., Puleo, J. A., 2008. Developing Terrestrial-LIDAR-Based Digital Elevation Models for Monitoring Beach Nourishment Performance. Journal of Coastal Research 4 (6), 1555-1564.

Pike, R. J., 1995. Geomorphometry - progress, practice, and prospect: Zeitschrift für Geomorphologie, v. Supplementband 101, 221-238.

Pike, R. J., 2000. Geomorphometry -diversity in quantitative surface analysis: Progress in Physical Geography 24 (1), 1-20.

Pirotti, F., Guarnieri, A., Vettore, A., 2013. Ground filtering and vegetation mapping using multi-return terrestrial laser scanning. ISPRS Journal of Photogrammetry and Remote Sensing 76, 56-63.

Rodríguez-Caballero, E., Afana, A., Chamizo, S., Solé-Benet, A., Canton, Y., 2016. A new adaptive method to filter terrestrial laser scanner point clouds using morphological filters and spectral information to conserve surface micro-topography. ISPRS Journal of Photogrammetry and Remote Sensing 117, 141-148.

Rosso, P. H., Ustin, S. L., Hastings, A., 2006. Use of lidar to study changes associated with Spartina invasion in San Francisco Bay marshes. Remote Sensing of Environment 100 (3), 295-306.

Ružić, I., Marović, I., Benac, Č., Ilić, S., 2014. Coastal cliff geometry derived from structurefrom-motion photogrammetry at Stara Baška, Krk Island, Croatia. Geo-Marine Letters 34 (6), 555-565.

Seymour, A. C., Ridge, J. T., Rodriguez, A. B., Newton, E., Dale, J., Johnston, D. W., 2018. Deploying Fixed Wing Unoccupied Aerial Systems (UAS) for Coastal Morphology Assessment and Management. Journal of Coastal Research 34 (3), 704-717.

Smith, A., Gares, P. A., Wasklewicz, T., Hesp, P. A., Walker, I. J., 2017. Three years of morphologic changes at a bowl blowout, Cape Cod, USA. Geomorphology 295, 452466.

Sofia, G., Hillier, J. K., Conway, S. J., 2016. Frontiers in Geomorphometry and Earth Surface Dynamics: possibilities, limitations and perspectives. Earth Surface Dynamics 4 (3), 721-725.

Wang, G., Philips, D., Joyce, J., Rivera, F., 2011. The Integration of TLS and Continuous GPS to Study Landslide Deformation: A Case Study in Puerto Rico. Journal of Geodetic Science 1 (1), 25-34. https://doi.org/10.2478/v10156-010-0004-5.

Wang, G., Joyce, J., Phillips, D., Shrestha, R., Carter, W., 2013. Delineating and defining the boundaries of an active landslide in the rainforest of Puerto Rico using a combination of airborne and terrestrial LIDAR data. Landslides 10 (4), 503-513. 
Westoby, M. J., Brasington, J., Glasser, N. F., Hambrey, M. J., Reynolds, J. M., 2012. 'Structurefrom-Motion' photogrammetry: A low-cost, effective tool for geoscience applications. Geomorphology 179, 300-314.

Wheaton, J. M., Brasington, J., Darby, S. E., Sear, D. A., 2010. Accounting for uncertainty in DEMs from repeat topographic surveys: improved sediment budgets. Earth Surface Processes and Landforms 35 (2), 136-156.

Williams, R., 2012. DEMs of difference. In: Cook, S.J., Clarke, L.E. \& Nield, J.M. (Eds.) Geomorphological Techniques (Online Edition). British Society for Geomorphology; London, UK. ISSN: 2047-0371.

Wright, L. D., Short, A. D., 1984. Morphodynamic variability of surf zones and beaches: A synthesis. Marine Geology 56 (1), 93-118.

Zhou, X., Wang, G., Bao, Y., Xiong, L., Guzman, V., Kearns, T. J., 2017. Delineating Beach and Dune Morphology from Massive Terrestrial Laser-Scanning Data Using Generic Mapping Tools. Journal of Surveying Engineering 143 (4), 04017008. 


\section{HIGHLIGHTS}

- TLS performs better than UAV over flat beach than in vegetated dunes and vice versa

- UAV-derived point clouds 30 times faster than TLS operations

- Survey design and post-processing methodology important in reducing DSM errors

- 3D surface derivation should take cognisance of terrain complexity and type 